\title{
Reconnaissance report and preliminary ground motion simulation of the 12 May 2008 Wenchuan earthquake
}

\author{
Louise Wedderkopp Bjerrum • Kuvvet Atakan • \\ Mathilde Bøttger Sørensen
}

Received: 13 October 2009 / Accepted: 6 July 2010 / Published online: 24 July 2010

(C) The Author(s) 2010. This article is published with open access at Springerlink.com

\begin{abstract}
The $M_{\mathrm{w}}=8.0$ Wenchuan earthquake of May 12, 2008, caused destruction over a wide area. The earthquake cost more than 69,000 lives and the damage is reported to have left more than 5 million people homeless. It is estimated that 5.36 million buildings were destroyed and 21 million buildings were damaged in Sichuan and the nearby provinces. Economic losses due to the event are estimated to be 124 billion USD. From a field reconnaissance trip conducted in October 2008, it is evident that the combination of several factors, including mountainous landscape, strong ground shaking, extensive landslides and rock-falls, has exacerbated the human and economic consequences of this earthquake. Extensive damage occurred over a wide area due to the shear size of the earthquake rupture combined with poor quality building construction. In order to investigate the ground shaking during the earthquake, we have conducted a strong ground motion simulation study, applying a hybrid broadband frequency technique. The preliminary results show large spatial variation in the ground shaking, with the strongest ground motions along the fault plane. The simulation results have been calibrated against the recorded ground motion from several near-field stations in the area, and acceleration values of the order of $1 \mathrm{~g}$ are obtained, similar to what was recorded during the event. Comparison with the damage distribution observed in the field confirms that the effect of fault rupture complexity on the resulting ground motion
\end{abstract}

L. W. Bjerrum $(\varangle) \cdot$ K. Atakan

Department of Earth Science, University of Bergen, Allegt. 41, 5007 Bergen, Norway

e-mail: louise.bjerrum@geo.uib.no

K. Atakan

e-mail: kuvvet.atakan@geo.uib.no

M. B. Sørensen

Helmholtz Centre Potsdam, GFZ German Reserch Centre for Geosciences, Section 2.6, Seismic Hazard and Stress Field, Telegrafenberg, 14473 Potsdam, Germany

Present address:

M. B. Sørensen

Department of Earth Science, University of Bergen, Allegt. 41, 5007 Bergen, Norway

e-mail: mathilde.sorensen@geo.uib.no 
distribution also controls to a large extent the damage distribution. The applied simulation technique provides a promising platform for predictive studies.

Keywords Damage distribution · Field reconnaissance · Ground motion simulation · Wenchuan earthquake

\section{Introduction}

The large May 12, 2008, Mw = 8.0 Wenchuan earthquake in the Sichuan province, was the deadliest earthquake in China since the Tangshan earthquake of 1976. The earthquake had disastrous consequences; it killed at least 69,227 people, injured 374,643 and 17,923 are still missing (presumed dead) as of May 2009. Economic losses due to the earthquake are estimated to be 124 billion USD (China.org.cn 2010).

The earthquake occurred along an approximately $300 \mathrm{~km}$ long system of northward dipping thrust and strike-slip faults in the Longmenshan Fold and Thrust Belt (LFTB). The epicenter was located in the southern part of the fault, near the city Yingxiu in Wenchuan County. The LFTB has developed as a result of the ongoing collision between the Indian and Eurasian plates and the eastward escape of the Tibetan Plateau. The LFTB marks the eastern termination of the deforming Tibetan Plateau and separates the Longmenshan Mountains in the west from the Sichuan Basin in the east. It also marks the transition from the thick $(65 \mathrm{~km})$ weak crust of the Tibetan plateau to the thinner (approximately $35 \mathrm{~km}$ thick), stronger crust underneath the Sichuan Basin (Zhao and Zhang 1987). The eastward motion of the Tibetan plateau is mainly accommodated by large east-west oriented strike-slip fault systems such as the sinistral Kunlun Fault in the north and the dextral Xianshuihe Fault in the south. The east-ward motion of the Tibetan Plateau decreases from approximately $14 \mathrm{~mm} /$ year to around $4 \mathrm{~mm}$ /year across the LFTB (Fig. 1).

During the instrumental period, large earthquakes in the eastern part of the Tibetan Plateau have been associated mainly with the east-west oriented fault systems. There have been several $M>7$ earthquakes during the last century, such as the $M=7.5$ Diexi earthquake in 1933 and two $M=7.2$ earthquakes near Songpang in 1976. Along the thrust faults of the LFTB, the largest expected earthquake was $M=7.3$ prior to the May 122008 Wenchuan earthquake (Zifa 2008). A probabilistic seismic hazard assessment by Zhang et al. (1999) indicated maximum expected ground motion along the LFTB to be $320 \mathrm{~cm} / \mathrm{s}^{2}$ at the 475 years return period. Highest seismic hazard in the eastern Tibetan Plateau was associated with the dextral Xianshuihe strike-slip fault (Zhang et al. 1999).

Following the earthquake in 2008, vertical displacement of 4-5 $\mathrm{m}$ and dextral displacement of up to $2 \mathrm{~m}$ at the surface along the fault were reported (Lin et al. 2009). The dextral displacement observed in the northern part of LFTB is consistent with the GPS velocity field, which shows a change in direction along the fold belt (Burchfiel et al. 2008). At the southern end of the fault, the compressional axis is perpendicular to the faults, resulting in reverse faulting mechanisms, whereas further north, the velocity field changes to be oblique or partly parallel to the main faults.

The Wenchuan earthquake, its aftershocks and a large number of triggered landslides are reported to have left more than 5 million people homeless. It is estimated that 5.36 million buildings were destroyed and 21 million buildings were damaged in Sichuan and the nearby provinces Chongqing, Gansu, Hubei, Shaanxi and Yunnan (USGS 2009). The high number of damaged buildings indicates bad construction practice and that many weak structures were built before the latest seismic design codes of China were implemented. The seismic design 


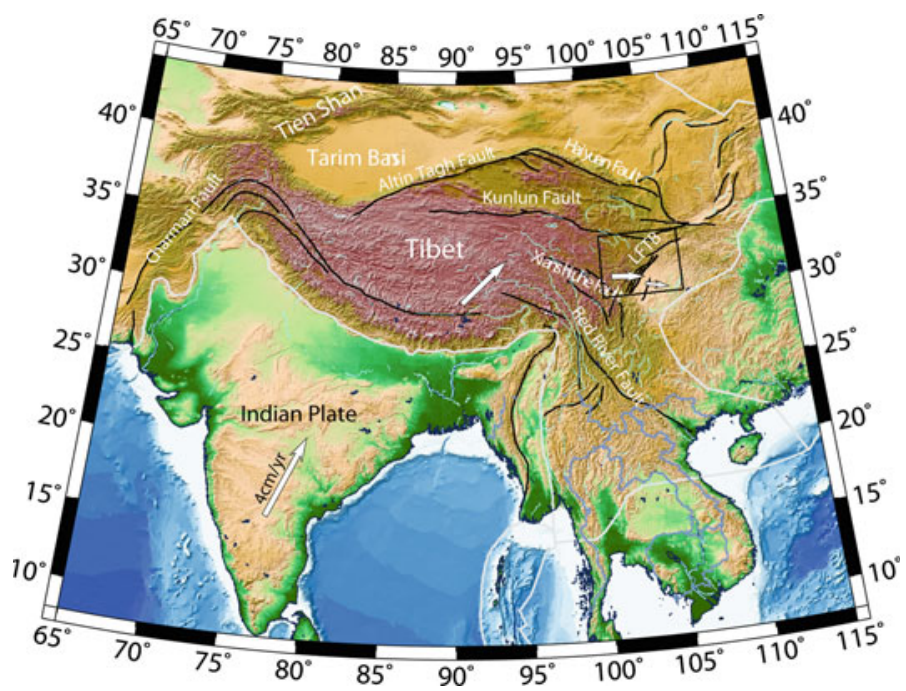

Fig. 1 The regional tectonic setting around the Tibetan Plateau, which is moving eastward as a result of the convergence of the northward moving Indian Plate $(4 \mathrm{~cm} / \mathrm{year})$ and the stable Eurasian Plate. The major plate boundaries are as thick grey lines along with the GPS vectors as white arrows, scaled after plate velocity. The main faults in the region are shown in black. The May 122008 earthquake occurred along the Longmenshan Fold and Thrust Belt (LFTB), marked with a black box

code has been revised several time, since it was first introduced in 1974 by the Chinese Construction Committee. Following the Mw = 7.9 Tangshan earthquake in 1976, the seismic design code was revised in 1978 and in 1989, the Chinese National Standard Seismic Code was introduced. The latest design code for buildings is from 2001. The area worst affected by the Wenchuan earthquake was classified as an intensity VII zone in the seismic zonation map (Zhao et al. 2009). As reported in the intensity map of the Wenchuan earthquake from the China Earthquake Administration, the intensity in the near fault area is determined to be IX-XI (Zhao et al. 2009), which is higher than the levels required by the seismic design code. Furthermore, the predominant frequency of the reported ground motion $(0.1-0.5 \mathrm{~s})$ is close to the fundamental frequency of masonry and reinforced concrete buildings of 5-6 floors, which dominate the structures in the area (Zhao et al. 2009; Zifa et al. 2008). These factors probably contributed significantly to the enormous number of collapsed and damaged buildings.

In this report, we give an overview of the earthquake characteristics and the associated damage from field observations of fault rupture, strong ground shaking, secondary effects (e.g. landslides, rock falls and liquefaction) as well as damage to buildings and infrastructure at selected sites. In addition, we present a preliminary simulation of the ground shaking during the event, based on the slip distribution provided by Ji and Hayes (2008), for the purpose of associating the strong ground motion with the observed damage.

\section{Field reconnaissance}

The field reconnaissance was conducted during a fieldtrip organized as part of the 14th World Conference on Earthquake Engineering, on 18 and 19 October, 2008. The field route was approximately $600-700 \mathrm{~km}$ long. We started from Chengdu and visited several major cities 


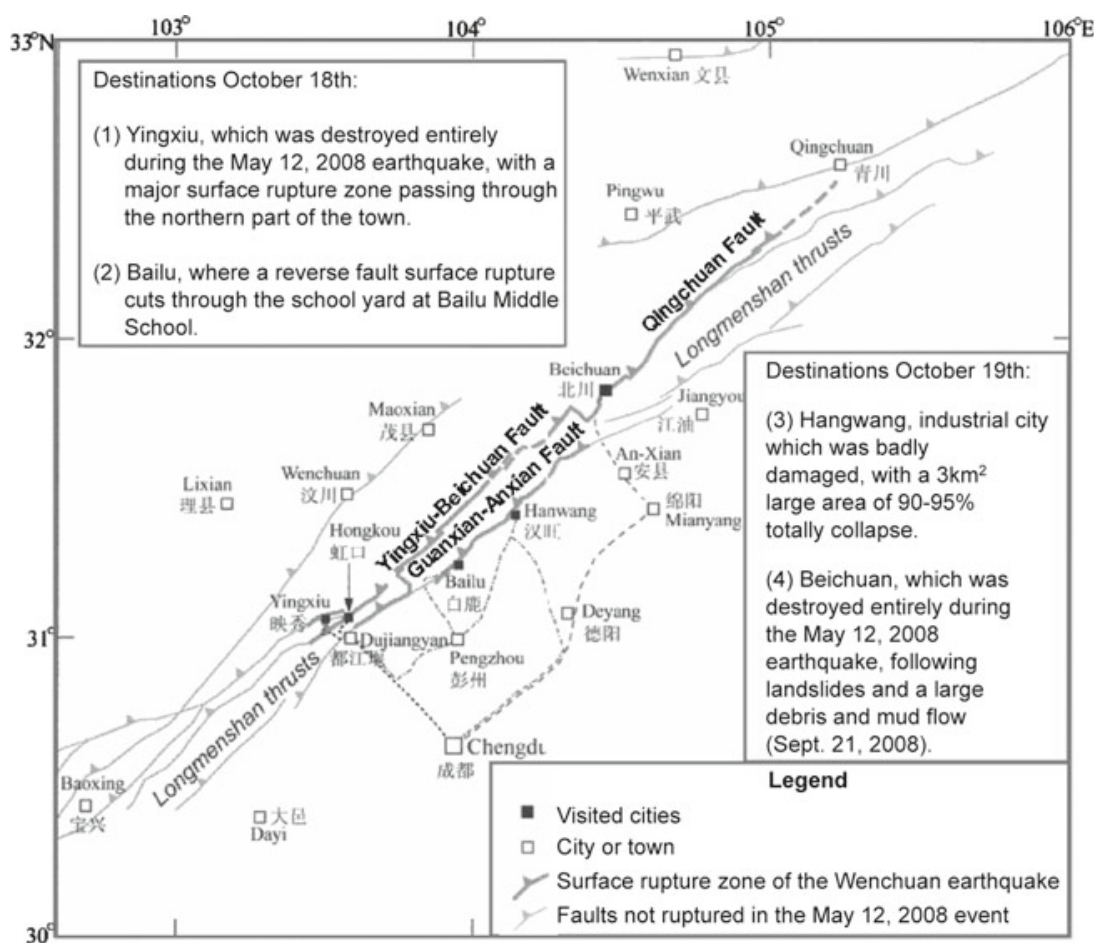

Fig. 2 Map of the area visited during the field trip with names of the ruptured faults. Field routes are described in the boxes. Modified from field-trip guide "Guide to the the Trip to the 5.12 Sichuan Earthquake Area for the 14th World Conference on Earthquake Engineering, Oct. 18-19, 2008”, edited by Earthquake Administration of Sichuan Province, China

affected by the earthquake, including Yingxiu, in the epicentral region and, Bailu, Hanwang and Beichuan, which are located along the fault rupture.

Bailu is located $40-50 \mathrm{~km}$ northeast of the epicenter, where the ruptured fault runs directly through the school yard of Bailu Middle School. Hanwang is located approximately $80 \mathrm{~km}$ northeast of the epicenter, in a large industrial area, whereas Beichuan (Qushan) is approximately $120 \mathrm{~km}$ northeast of the epicenter and has experienced many landslides and rock falls as well as a large debris flow following the earthquake. In the following sections, our main observations are described following the field trip route (Fig. 2) from the epicentral area in the south to Beichuan in the north.

\subsection{Yingxiu}

Yingxiu lies closest to the epicenter of the Wenchuan earthquake. The city suffered severe damage, and a clear surface rupture is seen in the northern part of the town. Before the earthquake, the population of Yingxiu and nearby areas was approximately 13,000. The death toll due to the earthquake is estimated to be around 5,000. Construction of new buildings was already planned at the time of the field trip and several large shelter towns had been established in the area.

The fault scarp in Yingxiu is located at $\left(31.065^{\circ} \mathrm{N} ; 103.490^{\circ} \mathrm{E}\right)$. The displacement observed was pure thrust with a vertical displacement of $1.8-2.2 \mathrm{~m}$ (Fig. 3). The fault has 

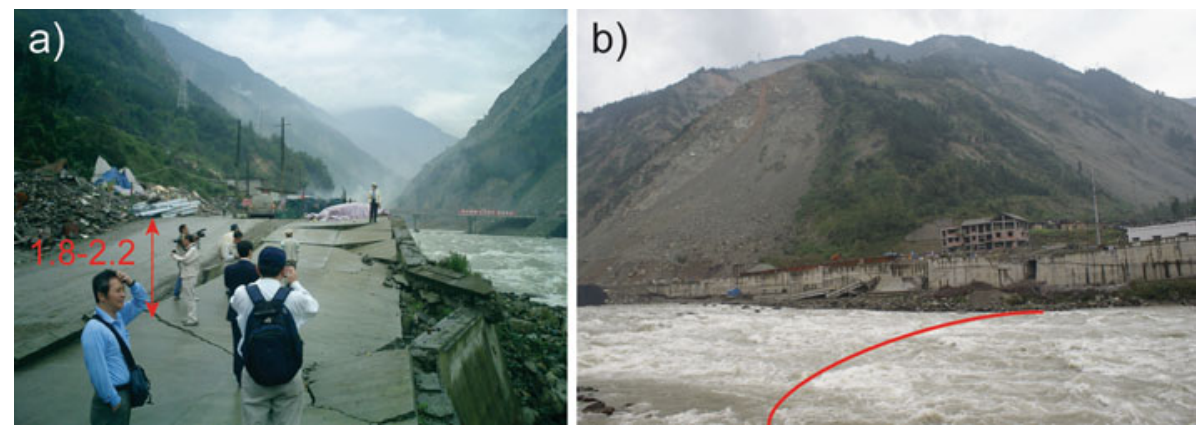

Fig. 3 Fault scarp, Yingxiu. a Surface rupture crossing and deforming the main road, which was flat prior to the earthquake. b Fault scarp continuing across the river. The approximate location of the surface rupture is shown by a red stippled line. A landslide scarp is visible on the hill side in the background

a strike of $240-250^{\circ}$ and a dip of $30-50^{\circ}$ at this location, crossing and deforming the main road (Fig. 3a). Eyewitnesses confirmed that the earthquake created a $2 \mathrm{~m}$ vertical scarp on the river bed, resulting in a small waterfall, which had gradually eroded away before our visit. In the background of Fig. 3b scarps after landslides are visible.

In Fig. 4, various types of building damage in Yingxiu are shown. Approximately $80 \%$ of the buildings in central Yingxiu collapsed during the earthquake, and it is planned that parts of the destroyed city will be preserved as a memorial museum. The massive destruction in Yingxiu is consistent with the short distance to the rupture initiation point from city and the thrust mechanism of the displacement. The high level of ground shaking experienced in the area was a consequence of proximity to the asperity with the largest displacement across the fault plane, estimated by waveform inversion (e.g. Ji and Hayes 2008; Nishimura and Yagi 2008; Zhao et al. 2010), as well as large displacements at the surface and is expressed through the damage to buildings and infrastructure (Fig. 4b). The buildings in the area were predominantly of reinforced concrete (RC) with brick infill (see Fig. 4a, the Xuankou Middle School, built in 2005 as an example). The damage observed varies from non-structural damage to total collapse of buildings. For further information on the damaged school buildings, see Zhao et al. (2009). Strong ground shaking is verified in Fig. 4c, where a factory building is clearly tilted and has been close to a collapse of the ground floor. The structures still standing had suffered heavy structural damage, ranging from soft storey collapse due to failure of columns (Fig. 4d-f) to partial collapse (Fig. 4g).

\subsection{Bailu}

In the city of Bailu, we visited the Bailu Middle School where the ruptured fault lies between two large school buildings (Fig. 5a,b, pictures are taken towards NE and SW, respectively). Here, the fault scarp has a minimum displacement of $1.5-2 \mathrm{~m}$ with a small dextral component $(0.2 \mathrm{~m})$. The strike of the fault is approximately $230^{\circ}$ with a dip of approximately $30-50^{\circ}$ at the position $31.211^{\circ} \mathrm{N} ; 103.913^{\circ} \mathrm{E}$. The two school buildings were not constructed at the same time. The building located on the hanging wall block (left in Fig. 5a) is from 2005, whereas the other one is older. Piles of rubble at each end of the school yard indicate total collapse of other smaller buildings that were located on top of the fault rupture. Studying details of the school buildings reveals that the large ground motions caused little or no damage to the new school building (Fig. 5c), whereas the older building has suffered non-structural 

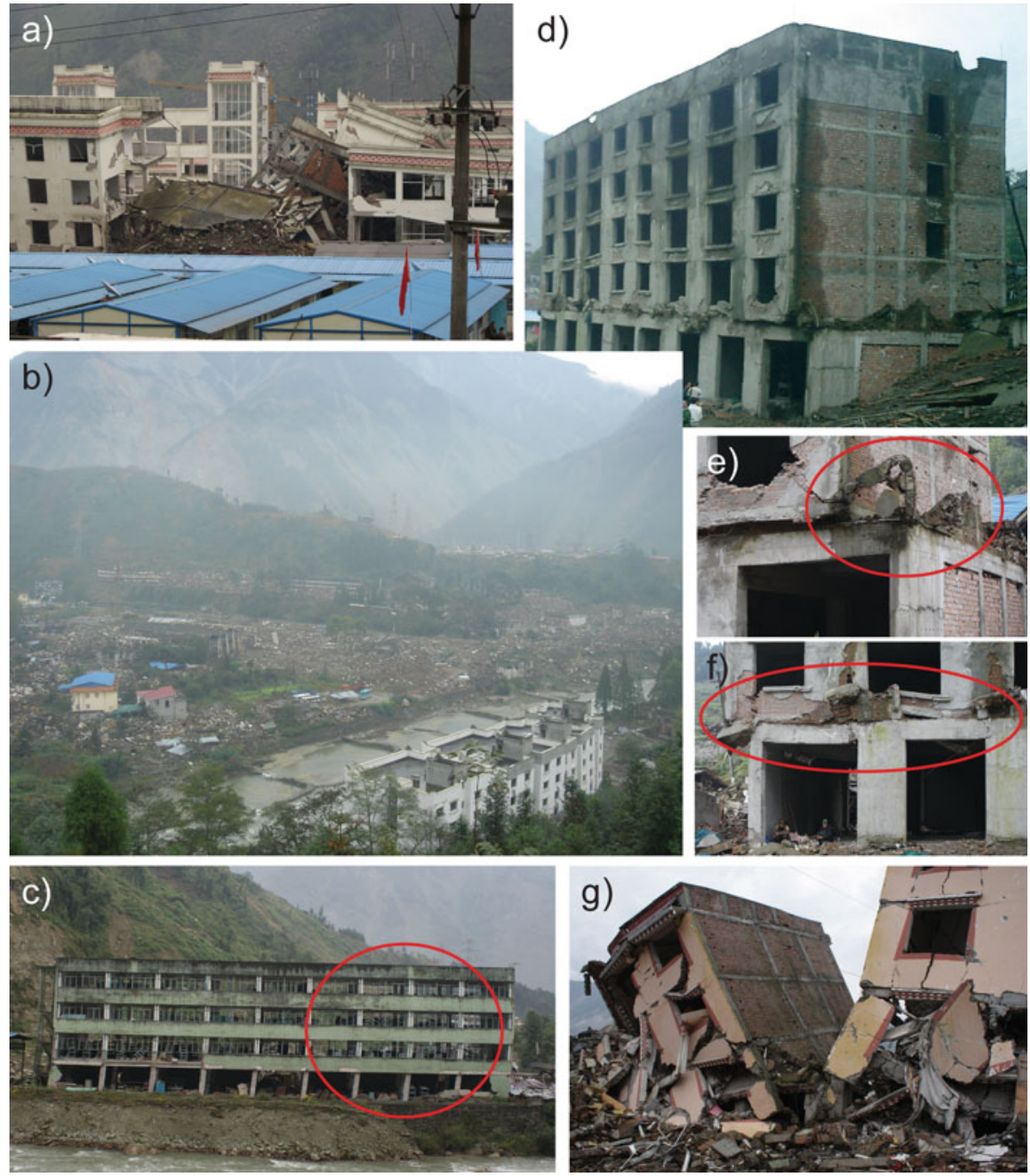

Fig. 4 Building damage at Yingxiu Town of Wenchuan County. a Xuankou Middle School, shelter buildings are visible in the foreground. b Overview of Yingxiu where ca. $80 \%$ of the city's buildings collapsed during the earthquake. $\mathbf{c}$ Factory building with clearly tilted columns. d-f Six-story RC-brick infill building which suffered a single story collapse of the second floor. $\mathrm{g}$ Partial collapse of residential buildings

damage in the infill walls as shear cracks, but also severe damage was observed as is evident by beam and column failure (Fig. 5d,e).

The maximum observed ground motion in the area was $633 \mathrm{~cm} / \mathrm{s}^{2}$. This was recorded on the vertical component at Bijiao station, approximately $70 \mathrm{~km}$ from the epicenter ( $\mathrm{Li}$ et al. 2008a). In Bailu, there was widespread damage to buildings and infrastructure. The historical masonry bridge (Zhongfa) connecting the Bailu Middle School to the city (Fig. 6a) collapsed during the earthquake. The hospital building of Bailu was damaged and the roof collapsed (Fig. 6b). The remaining buildings, which apparently did not suffer any structural damage, were still in use, although there were clear signs of cracks on the brick-walls (Fig. 6c,d). The 

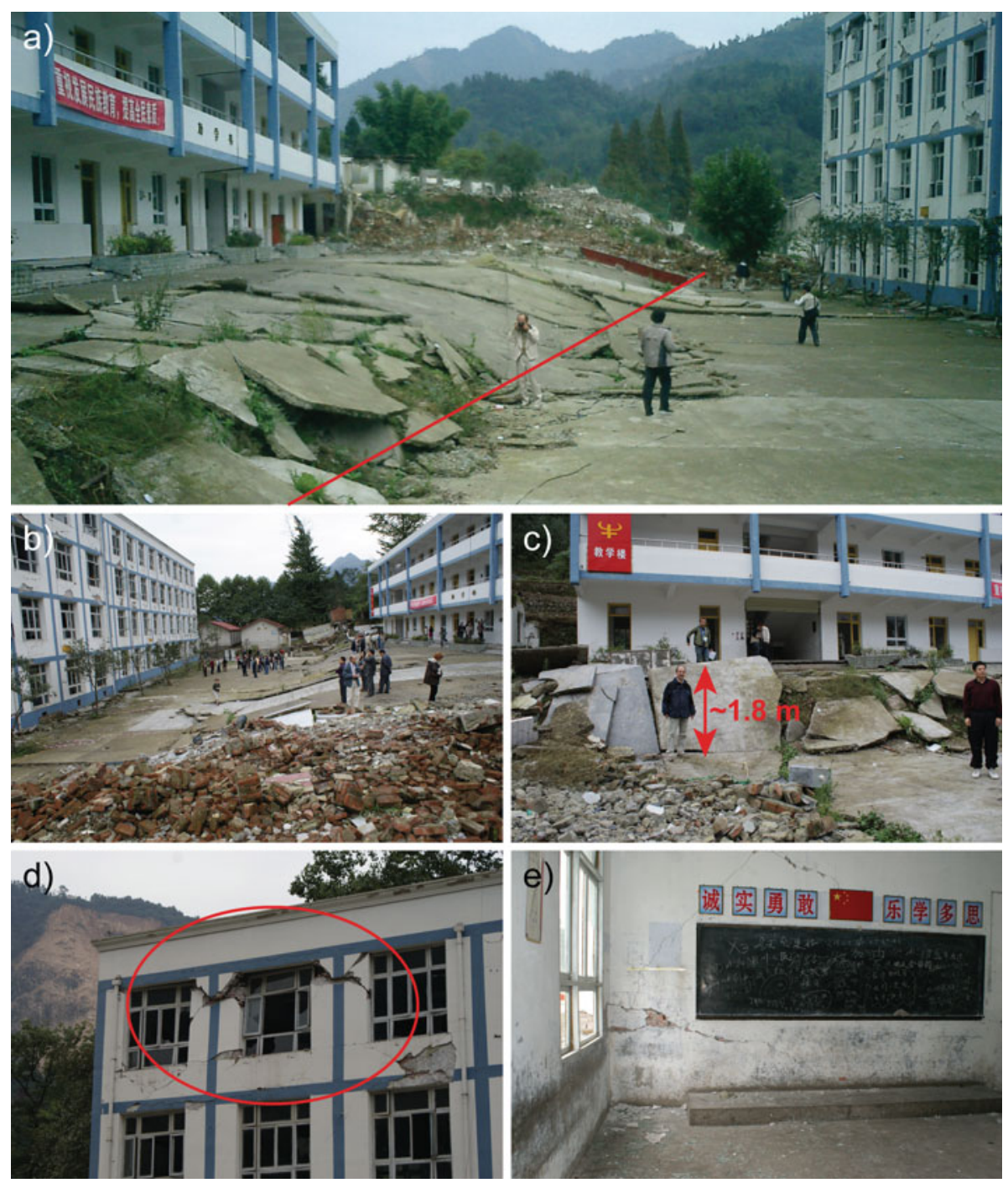

Fig. 5 Damage of Bailu Middle School buildings and fault scarp in Bailu. a-b School yard, taken towards northeast and southwest, respectively. c Newer school building on the hanging wall block with no visible damage. Vertical uplift of approximately $1.8 \mathrm{~m}$ is visible. d Structural failure of cross diagonal fractures on the older school building. e View from inside the older school building, where wall cracks are visible

population who survived the earthquake was provided with temporary shelters (tents in the background of Fig. 6c).

\subsection{Hanwang}

Before the Wenchuan earthquake, Hanwang was a large industrial city with 70,000 inhabitants. During the earthquake, 4,500 died and there were still many missing in October 2008. In an area of approximately $3 \mathrm{~km}^{2}$ in the central part of Hanwang, 90-95\% of the buildings 

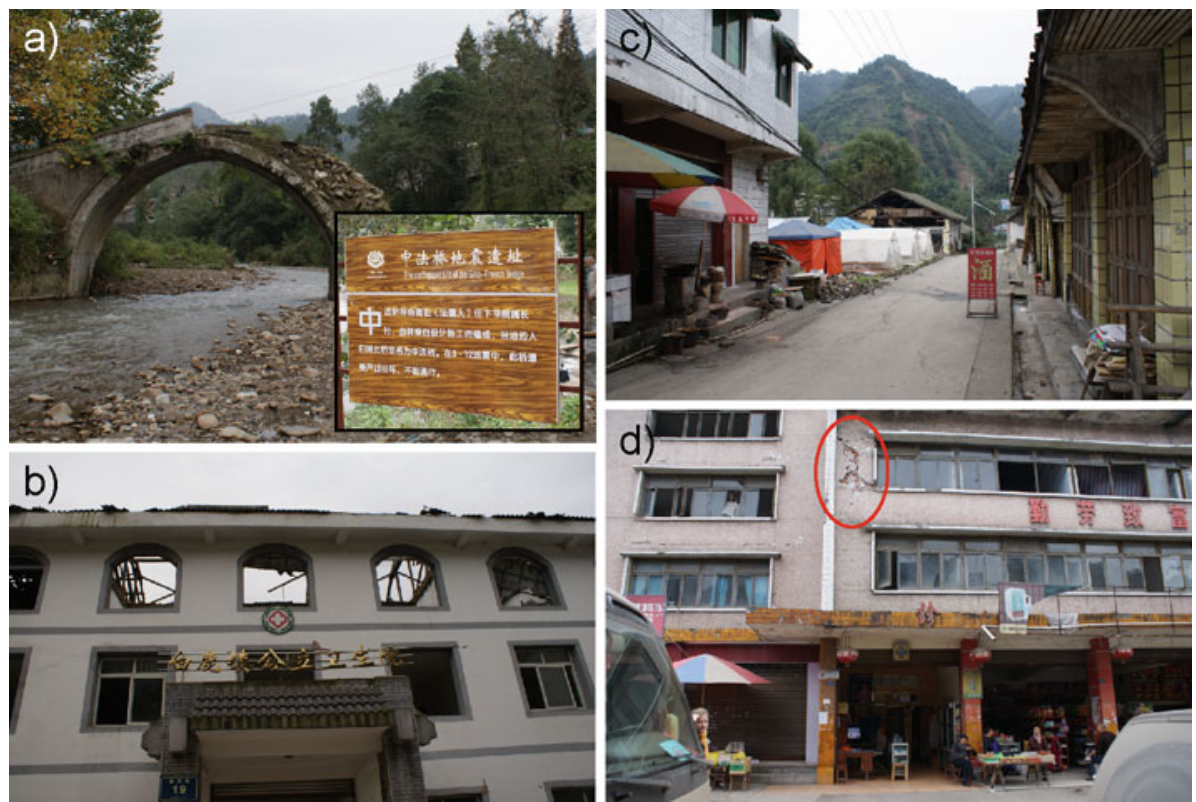

Fig. 6 Damage to structures in the city of Bailu. a Zhongfa Bridge crossing the river in Bailu. b City hospital, which suffered from roof collapse. c-d Main street of Bailu, where large cracks are visible in the house walls. Temporary shelters and tents are visible in the background of $\mathbf{c}$

totally or partially collapsed, resulting in a large uninhabitable area. The plans for this area are to protect the damaged parts, and preserve it as a memorial earthquake park.

The nearest ground motion records to Hanwang were recorded at Qingping station, approximately $90 \mathrm{~km}$ from the epicenter, with values of more than $800 \mathrm{~cm} / \mathrm{s}^{2}$ on the two horizontal components ( $\mathrm{Li}$ et al. 2008a). The fault scarp in Hanwang is visible near the market area $\left(31.460^{\circ} \mathrm{N} ; 104.163^{\circ} \mathrm{E}\right)$, where the orientation of the fault is measured to be approximately $260^{\circ}$ with a dip of $30-40^{\circ}$. The vertical displacement was estimated to be about $1.5 \mathrm{~m}$.

The clock tower shown in Fig. 7a has become a symbol of the Wenchuan earthquake, since it stopped at the time of the earthquake (14:28 local time). There was no apparent damage to this structure. The photographs in Fig. 7b-e are from the most heavily damaged area in the central part of the town. Non-structural shear cracks were observed in several buildings where the joints between the columns and beams seemed intact (Fig. 7b). Many residential buildings of 4-5 stories suffered substantial damage in the area. An example of a soft storey collapse, of an apartment building is illustrated in Fig. 7c. In this residential building complex, the staircases between the apartment blocks also collapsed, leaving no exit for survivors.

In the central area of Hanwang, almost all non-engineered adobe structures completely collapsed, whereas the newer reinforced concrete buildings seem to have been able to withstand the strong ground shaking (Fig. 7d,e), for example, the main building of Dong Fang Steam Turbine Factory (Fig. 7f).

This area of Hanwang also includes the old market area. Most structures here were simple two-storey reinforced concrete buildings with a flat roof, where the ceiling height of the ground floor was larger than the ceiling height of the second floor. These buildings suffered severe damage due to failure of beam and column joints. As a result, there were significant volumes of rubble and construction material (piles up to $2 \mathrm{~m}$ high) in the streets (Fig. 8). 

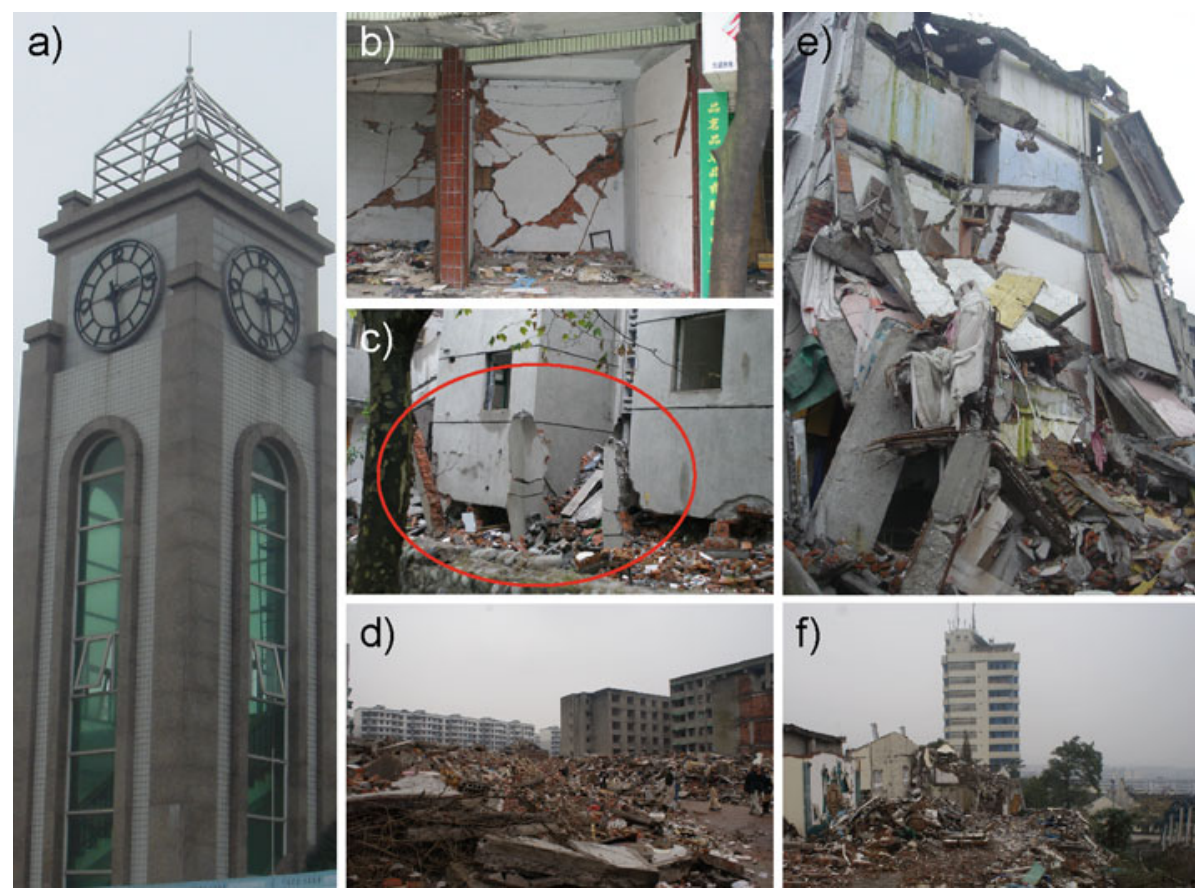

Fig. 7 Building damage in Hanwang. a City clock tower of Hanwang with no apparent damage. The clock stopped at the time of the earthquake, 14.28 (local time). b View inside a building, with visible non-structural damage. c Single story collapse of apartment building. d-e Widespread damage of poorly constructed buildings, whereas modern buildings sustained the ground shaking. f Main building of Dong Fang Steam Factory with no apparent damage. In the foreground widespread damage and collapse of poorly constructed buildings is visible

\subsection{Beichuan}

The city of Beichuan had a population of 22,000 before the Wenchuan earthquake. During the earthquake approximately 10,000 people died, 2,000 were injured, and in October 2008 approximately 1,900 were still missing. Almost all families in Beichuan lost family members as a result of the earthquake. Beichuan is located in a narrow valley between steep mountains and the city sustained additional damage due to several landslides. Later, a debris- and mudflow caused by heavy rainfall following the earthquake further devastated the area. This event, which occurred on September 21, 2008, is described in a separate section.

After the earthquake all communication lines were destroyed and the major roads leading out of the city were either destroyed or blocked by landslides and rock falls, leaving Beichuan cut off from the surrounding region for several days. The population therefore had to survive by their own resources, and witnesses have accounted that because of the rugged topography, 10-12 people were needed in order to transport one injured person out of the city valley.

The ground motions in Beichuan exceeded $350 \mathrm{~cm} / \mathrm{s}^{2}$ during the earthquake, with the largest ground motions on the vertical component (Li et al. 2008b). The fault scarp runs through the city in the area between the old and the new part of town $\left(31.829^{\circ} \mathrm{N} ; 104.457^{\circ} \mathrm{E}\right.$, Fig. 9). The strike of the fault is found to be $230-240^{\circ}$, and the vertical displacement was 2-2.5 m. Scarps due to the extensive landslides covered the mountain sides, and part of the 

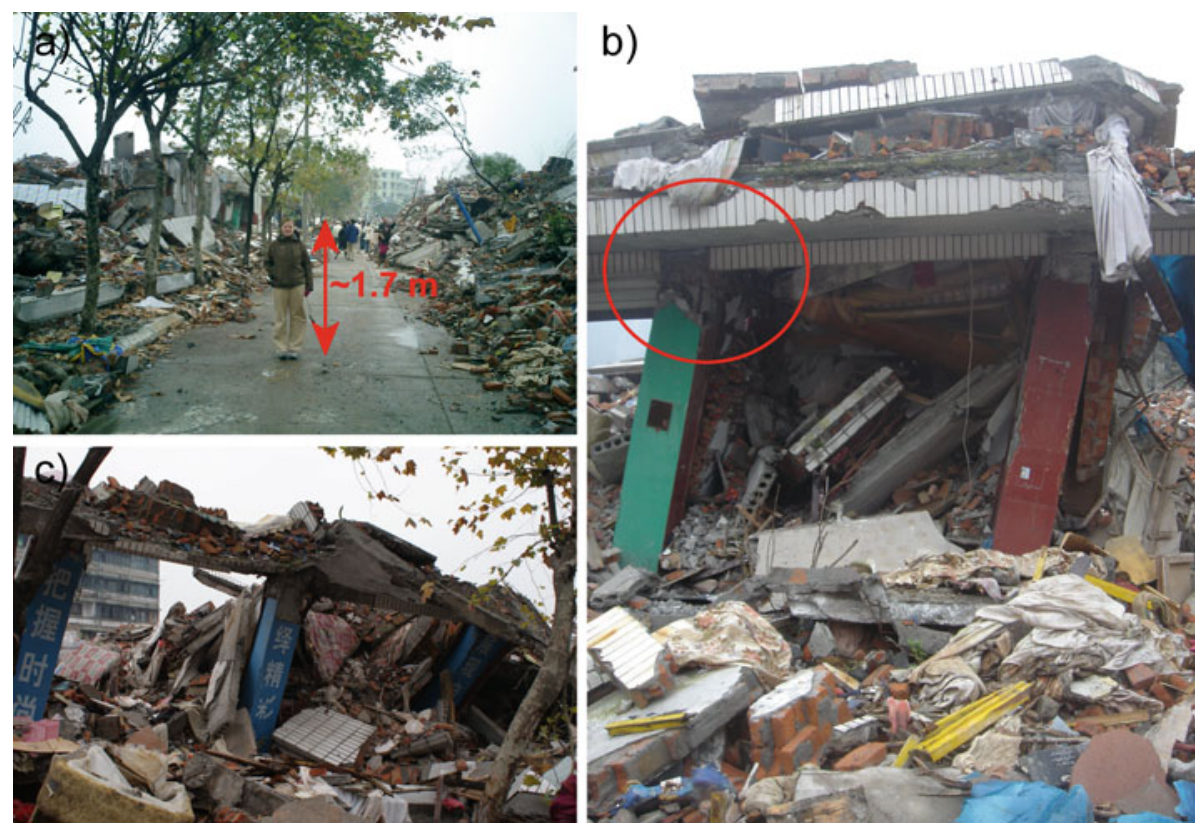

Fig. 8 Typical market buildings with shops on the ground floor and apartments on the second floor, Hanwang. a View through the main street of the market area. b Close-up of the structural damage of the beam-column joints in a market building. c Front of market building is partial collapsed while the rest of the building is totally destroyed

river running through the city was filled with newly formed alluvial material as a result of the landslides (foreground of Fig. 9a).

Various types of building damage are observed in Beichuan, ranging from non-structural damage to total or partial collapse (Fig. 10). The Bei Chuan Hotel sustained the strong ground shaking and did not collapse. However, failures at the column beam joints are visible and the hotel is no longer habitable (Fig. 10a, b). In the main street of the new part of Beichuan (Fig. 10c-e), weak structures, with partly open-ground storey, have partially or totally collapsed due to column failure, whereas the more resistant apartment blocks, without open-ground storey, have no apparent structural damage. The building in Fig. 10f, located in the main street, suffered from soft-story collapse. Note that the glass façade of the building is almost intact. Other examples of damage to structures in Beichuan are collapse of soft stories as well as tilting and toppling of apartment blocks indicating ground failure (Fig. 10g,h). Throughout the city, survivors were still trying to recover their belongings from the damaged buildings and rubble at the time of our visit (Fig. 10a, e).

\subsection{Damage to in infrastructure and special structures}

During the survey, we also visited sites where damage to infrastructure had occurred, e.g. collapsed roads, as well as damaged and undamaged long-span or high-rise structures. The performance of some of these special structures is described here.

On the road from Chengdu to Yingxiu, the Baihua Bridge ("Hundreds of Flower" Bridge) collapsed at the entrance to Yingxiu $\left(31.045^{\circ} \mathrm{N} ; 103.474^{\circ} \mathrm{E}\right)$ due to failure of the bearing 

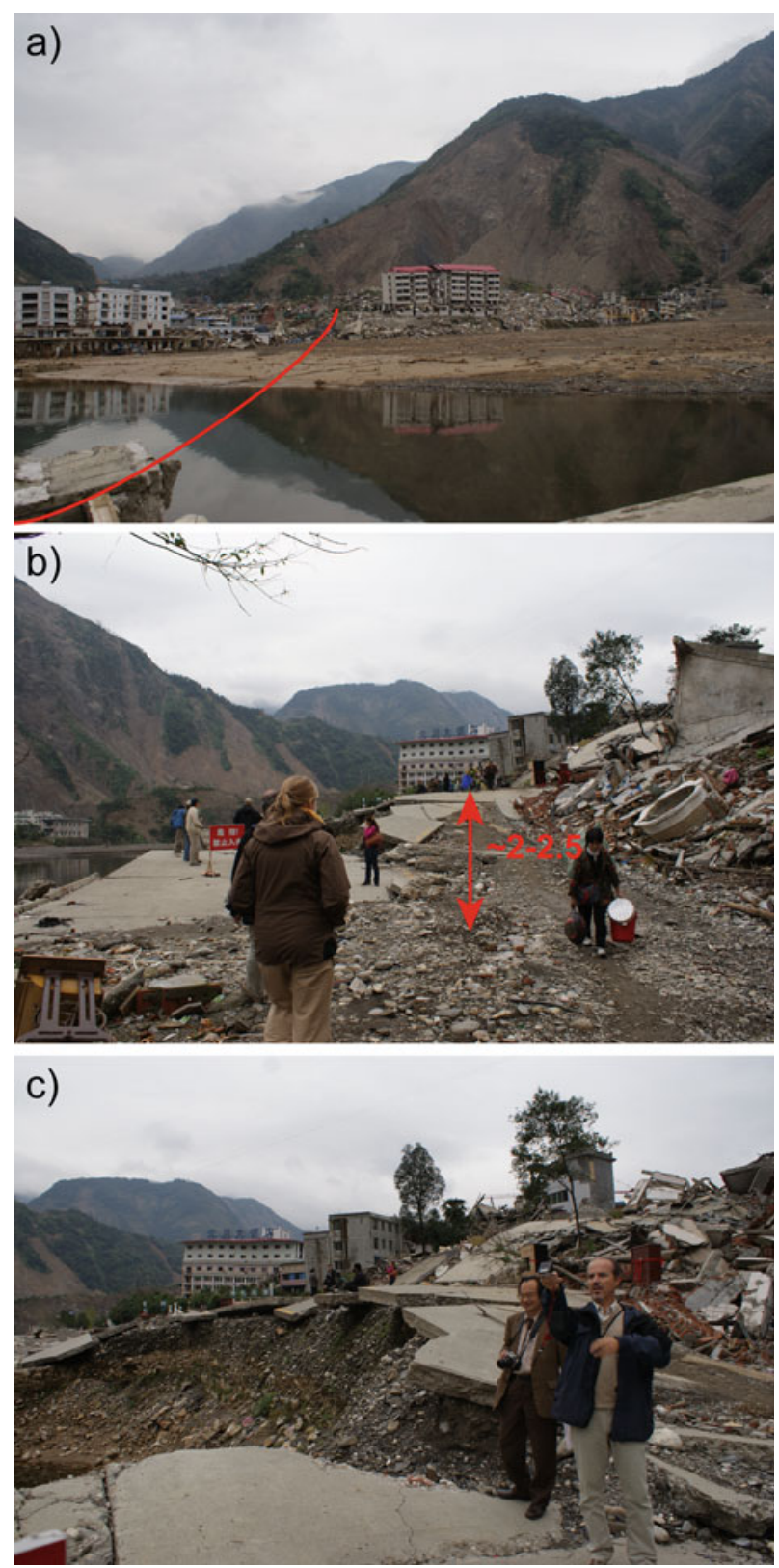

Fig. 9 Fault scarp in Beichuan, crossing the river with a $2.5 \mathrm{~m}$ uplift. a View towards SW, the old part of Beichuan with alluvial material in the foreground, the red line marks the continuation of the fault across the valley. b Surface rupture in Beichuan. The picture is taken towards the new part of town to the NE, at the same location as (a). Vertical uplift of $2-2.5 \mathrm{~m}$ was measured in Beichuan, as indicated with the red arrow. c Close-up of the fault scarp, where deformed concrete road blocks and rubble from collapsed buildings are visible 

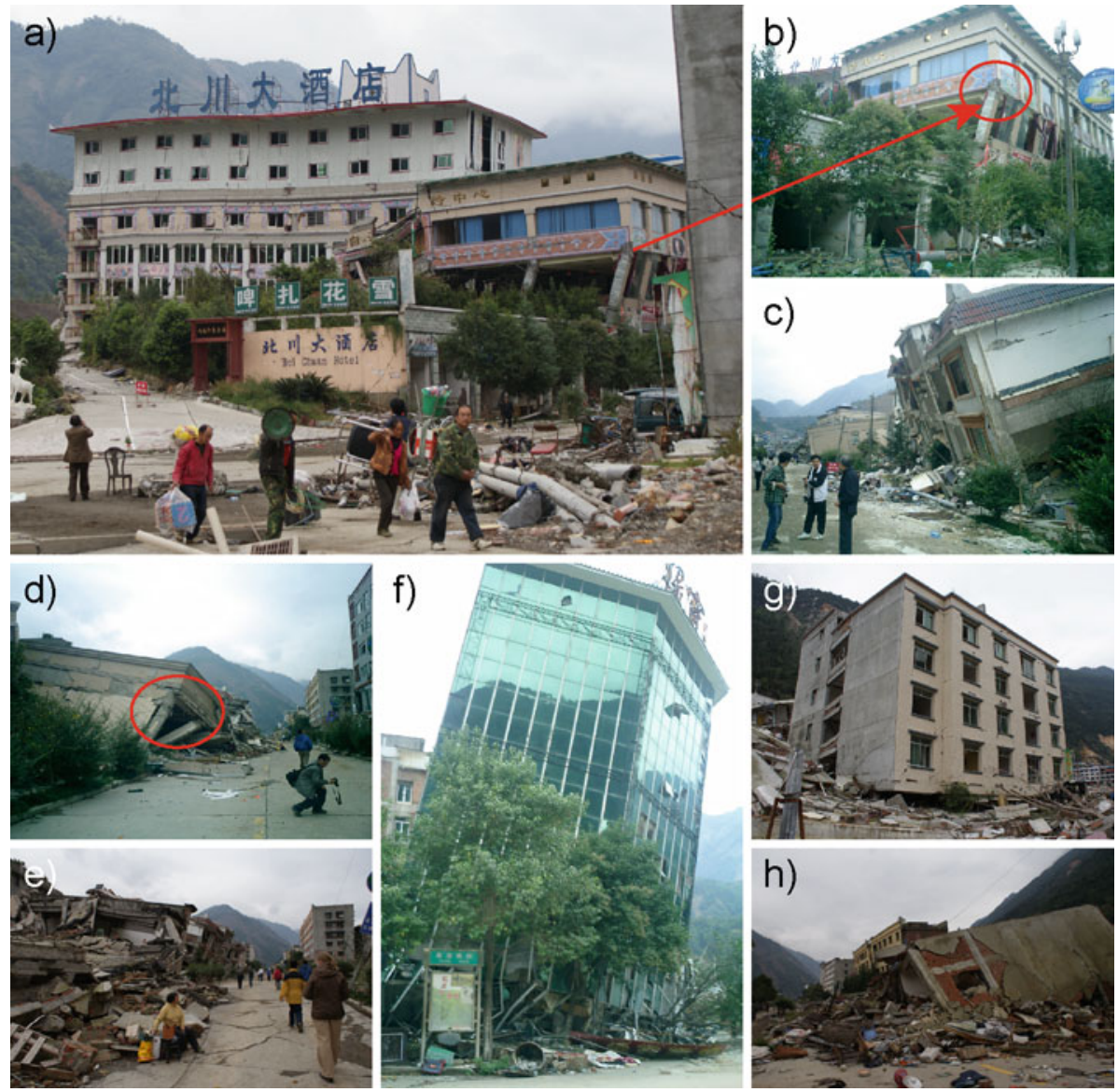

Fig. 10 Building damage in Beichuan County Town. a-b Bei Chuan Hotel suffered severe damage, as failure of the column beam joints, but sustained the ground shaking. The main building of the hotel is clearly tilted (a). c-e Main street of the newer part of Beichuan, with collapse of weak structures due to column failure. $\mathbf{f}-\mathbf{g}$ Buildings suffering single story collapse of the first floor. $\mathbf{h}$ Toppled building due to ground failure

columns (Fig. 11). The failure of the bridge further complicated the access to the area, hindering emergency rescue efforts.

In the industrial city of Hanwang, the large-span buildings of the Dong Fang Steam Turbine Factory suffered varying degrees of damage (Fig. 12). The older brick buildings experienced roof collapse and partial collapse of walls. However, the main structure and the columns are intact and still standing (Fig. 12a,b). The gymnasium of the turbine factory, a steel-structure, was intact after the earthquake (Fig. 12c).

High-rise structures suffered varying degrees of damage. As an example, the water tower of the Shifang Cement Plant (located in Hanwang), approximately 15-20 m high and with a large mass on top (Fig. 13a), is intact after the earthquake, although nearby buildings were severely damaged. Figure 13b, on the other hand, shows another factory in Hanwang where the chimney has been damaged near the top. The nearby factory buildings have been heavily damaged, with partial collapse of some walls. Also long-span structures, such as bridges and dams, experienced varying levels of damage. Damage to bridges varies from total 

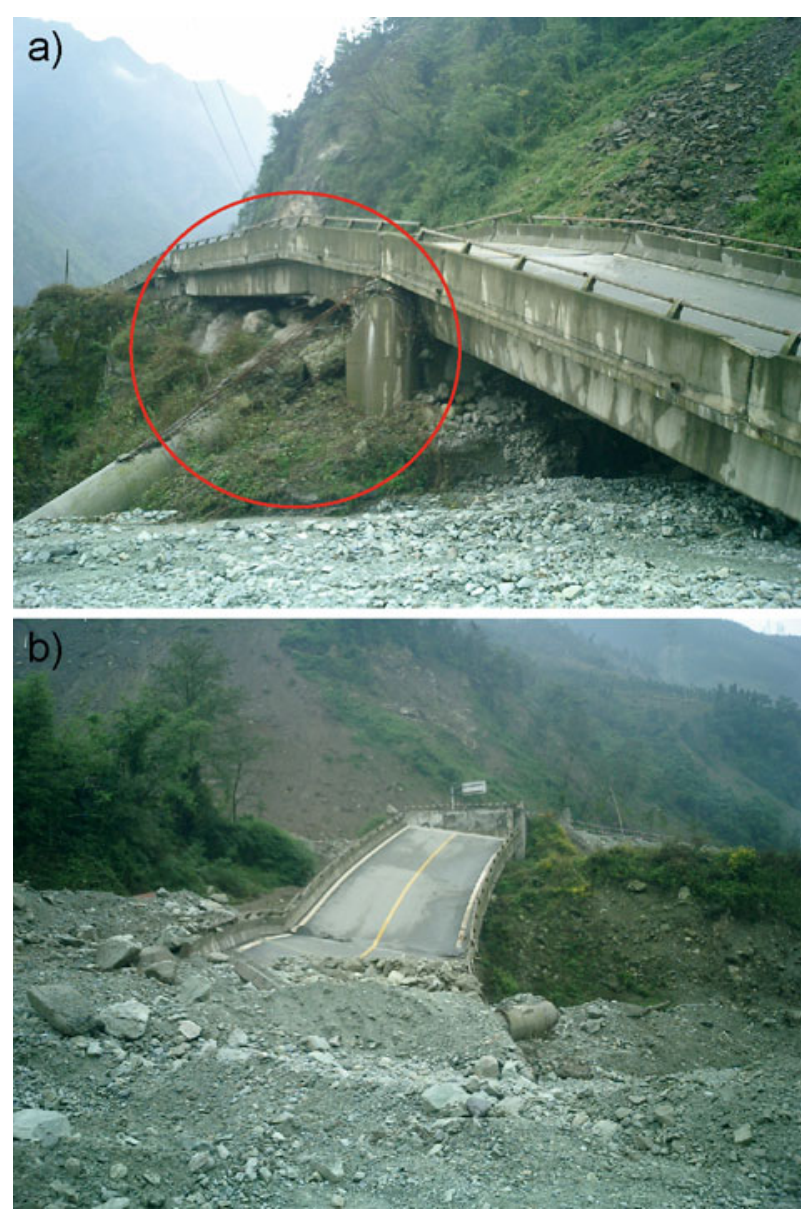

Fig. 11 Structural damage to the highway between Chengdu and Yingxiu. a View towards Chengdu. A collapsed column is visible in the lower left corner. b View towards Yingxiu, where the road section in the foreground is dislocated and separated from the section in the background
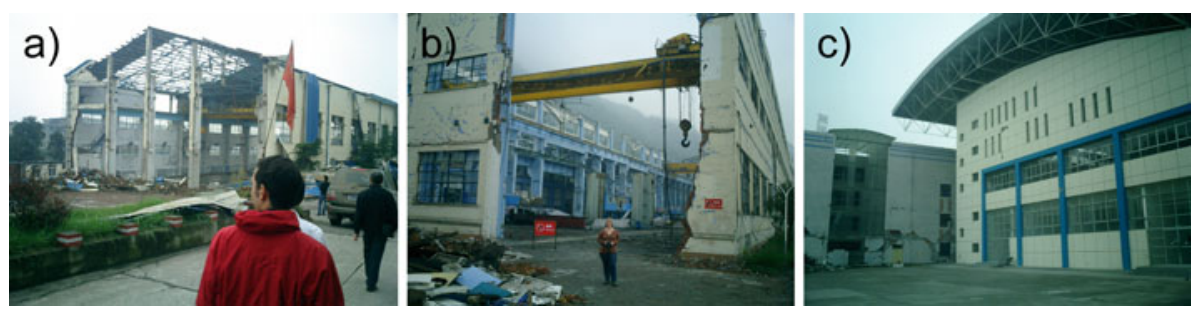

Fig. 12 Factory buildings of the Dong Fang Steam Turbine Factory. a-b Older factory buildings, which suffered from substantial damage as roof collapse. c The gymnasium of the factory, which is a newer steel structure, had no apparent damage after the earthquake

collapse, such as an older bridge located near the surface rupture in Hanwang (Fig. 14a), to no damage. The Zipingpu Dam was slightly damaged due to displacement of the dam (vertical settlements of $73 \mathrm{~cm}$ and horizontal displacements of $38 \mathrm{~cm}$ have been observed after 
Fig. 13 High-rise structures. a Water tower of Shifang Cement Plant in Hanwang. b Slightly damaged factory chimney in Hanwang

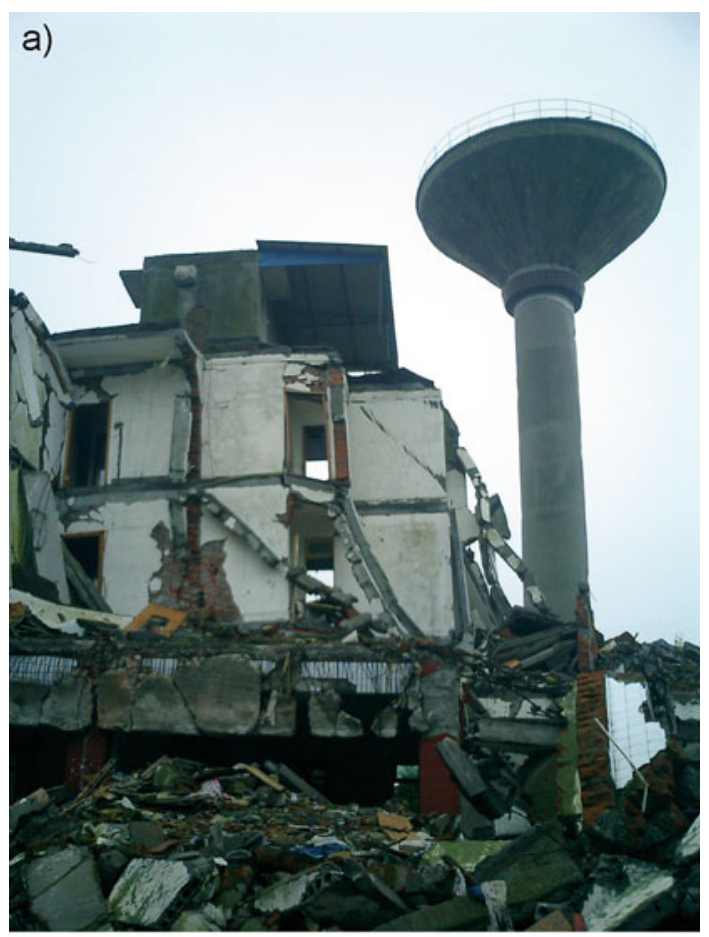

b)

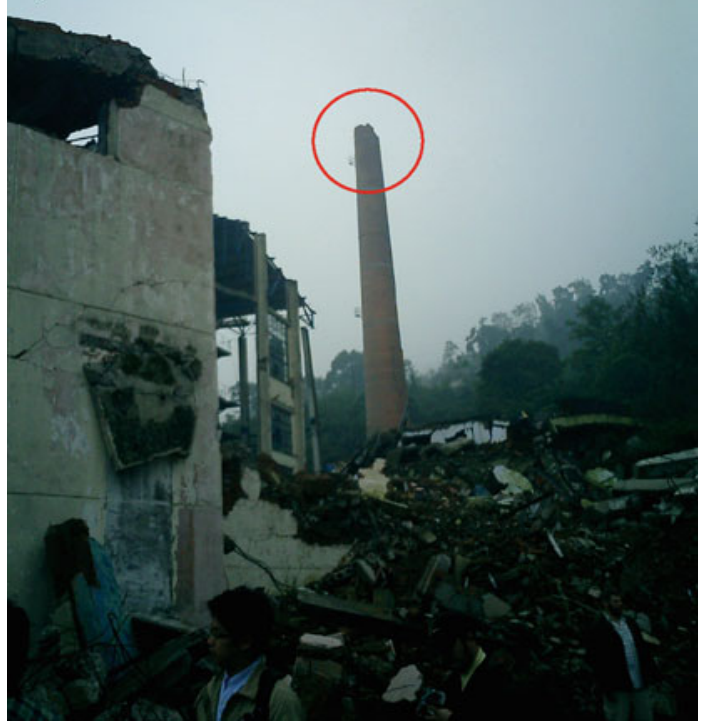

the earthquake) (Zhang et al. 2009). However, the main structure of the dam remained intact (Zifa et al. 2008) (Fig. 14b). Construction of the Zipingpu dam was completed in October 2005, and the reservoir reached a water level of $875 \mathrm{~m}$ above sea level in October 2006 and again in November 2007 (Zhang et al. 2009). Several authors have discussed whether this 

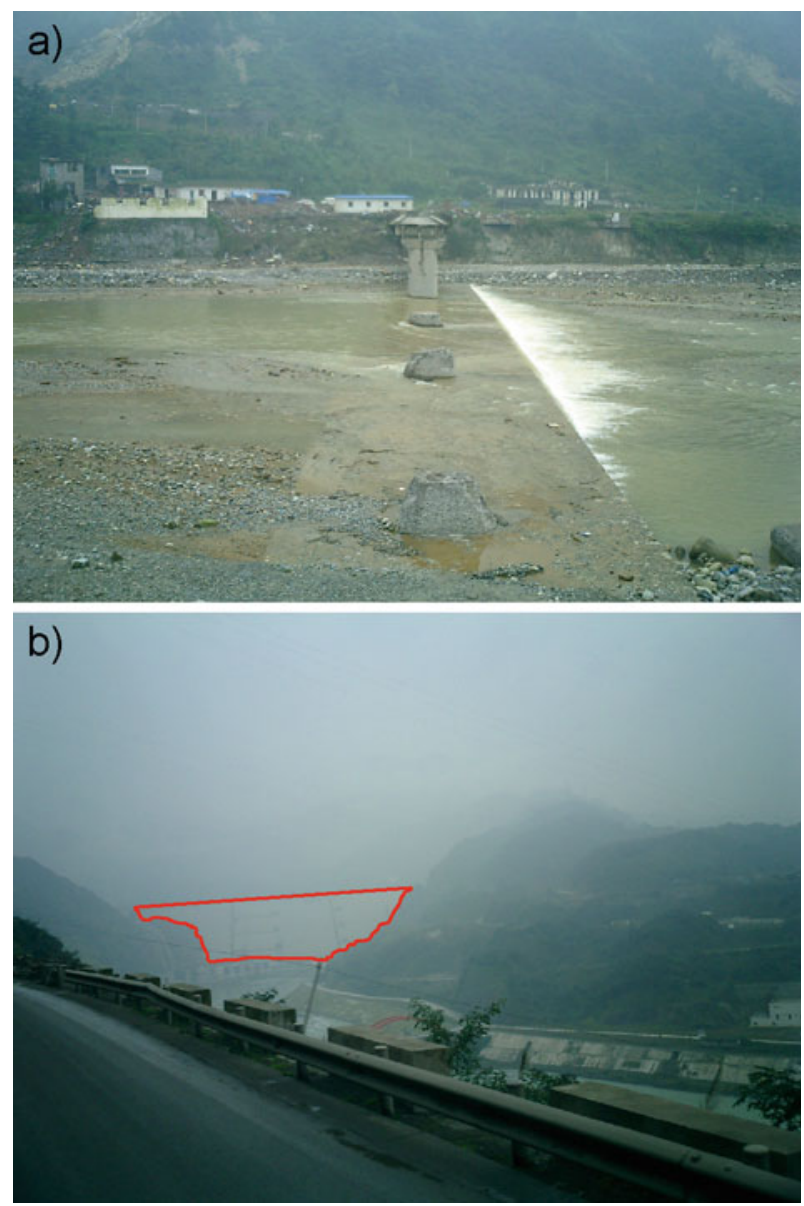

Fig. 14 Long-span structures. a Bridge crossing the river in Hanwang, notice that the foundation of the bridge has no apparent damage. b Zipingpu Dam. The silhouette of the dam structure is barely seen in the background, marked with a red line. Picture is taken upstream towards north

has had a triggering effect on the seismicity in the area (e.g. Lei and Kuwahara 2008; Kerr and Stone 2009; Zhang et al. 2009).

\subsection{Secondary effects after the Wenchuan earthquake}

Numerous secondary effects have been documented and there are at least 15,000 instances of landslides, rock falls, debris flows and mudslides. These effects are estimated to have caused more than 20,000 fatalities (Yin et al. 2009). This is seen clearly at Beichuan. The city sustained heavy damage due to strong ground shaking from the main shock and later by aftershocks. Additional damage was caused by the following landslides and rock falls from the steep mountains that surround the city. The area was further impacted by a widespread debris- and mudflow on September 21, 2008. Figure 15 shows Beichuan before and after the earthquake, as well as after the debris flow. Houses can be identified in the three pictures for correlation. The extent of the debris flow was widespread and comparing Fig. 15b,c clearly 
Fig. 15 Overview of Beichuan County Town. a Photo of the town Beichuan before the May 12, Wenchuan earthquake (photo source unknown). b Photo of the town Beichuan, taken in July 2008, after the May 12 Wenchuan earthquake. (Photo by Dr. Gonghui Wang, Kyoto University, Japan). $\mathbf{a}$ and $\mathbf{b}$ are from the homepage of USGS Landslide Hazard Program (2009). c Photo of Beichuan, taken in October 2008, after the debris- and mudflow
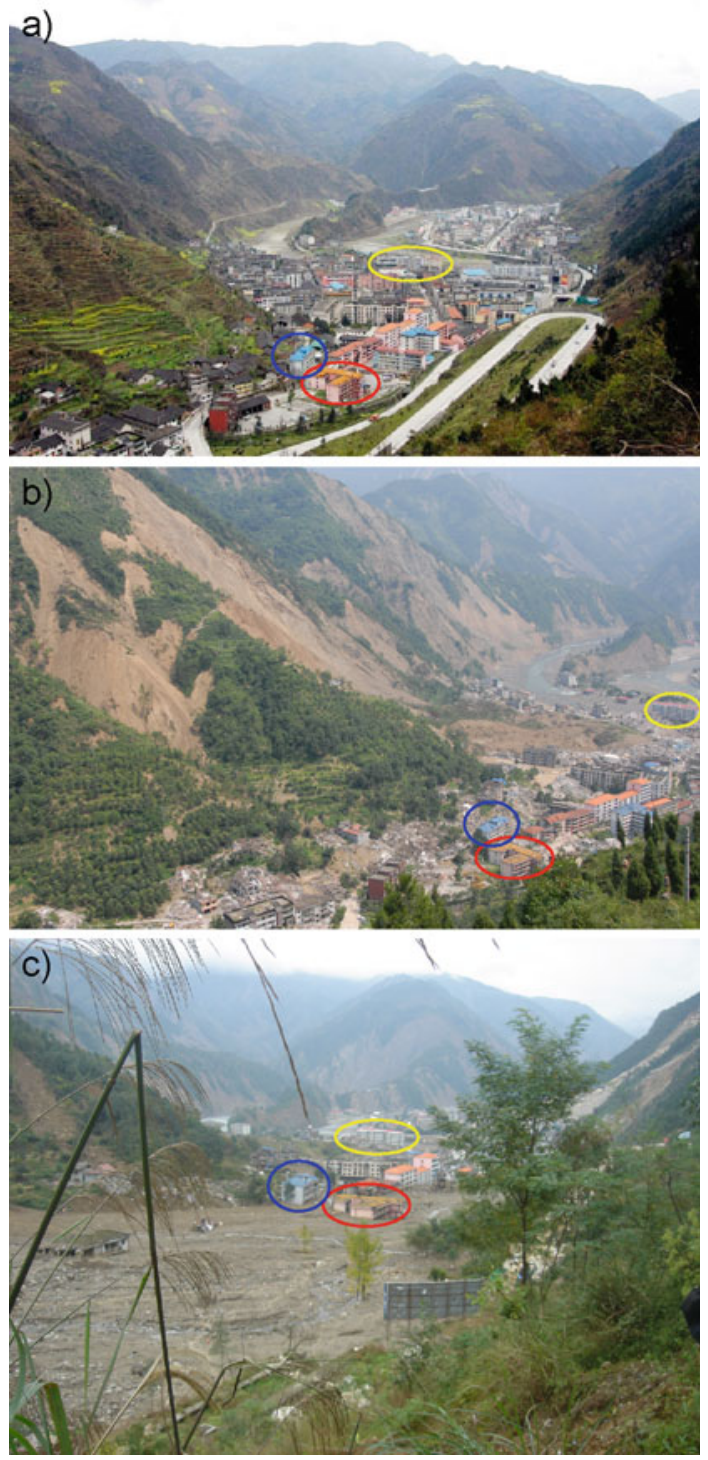

shows how the area is overlain by debris material and further damaged by the debris flow. More examples from the Beichuan area are presented in the following paragraphs.

\subsubsection{Rock slides and landslides}

The steep slopes of the mountains in the entire earthquake affected region (the mountain front rises about 4,500 m over a horizontal distance of $100 \mathrm{~km}$ across the Longmenshan Mountains), combined with the likely amplification of strong ground motion in the mountain topography, are important factors for the large amount of triggered landslides following the Wenchuan earthquake. In the area near Yingxiu and the water reservoir for the Zipingpu Dam, the large 

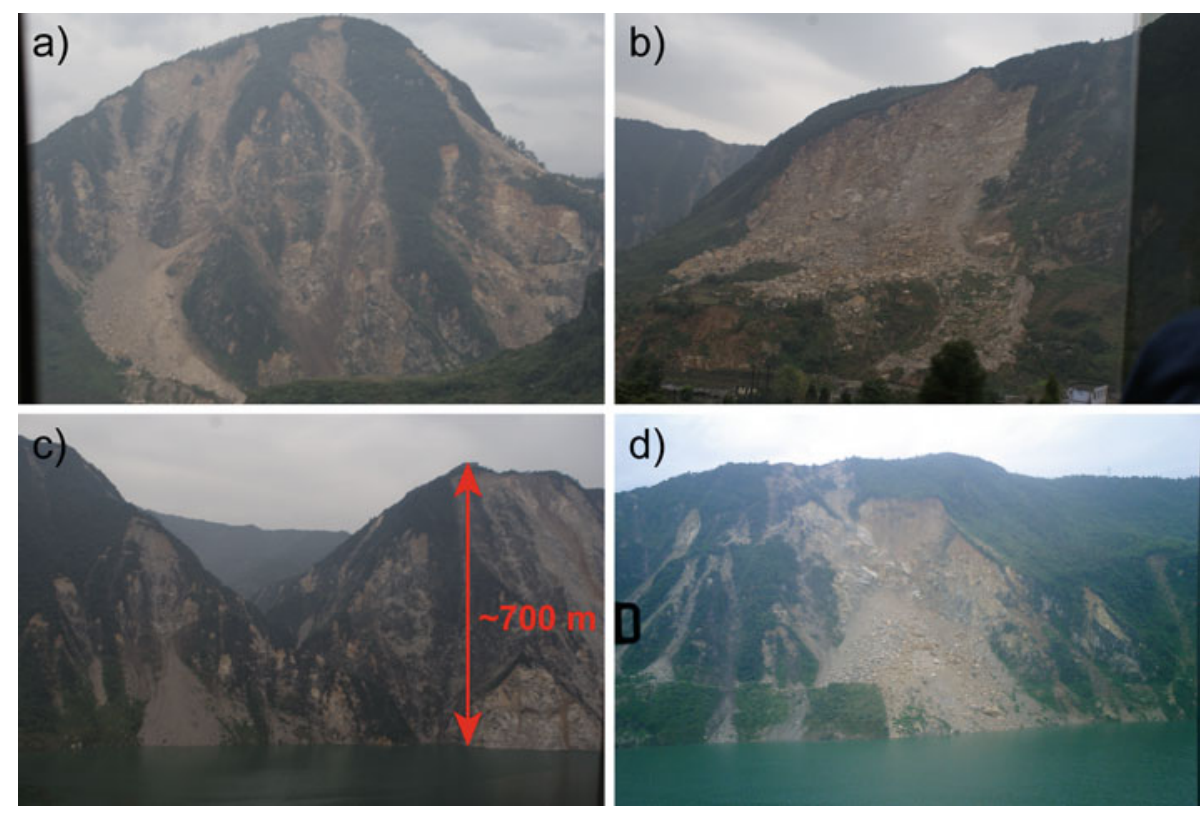

Fig. 16 Landslide scarps near Yingxiu. The vertical distance from the water level to the top of the mountain is in these pictures roughly estimated to be $700 \mathrm{~m}$. a-b Landslide scarps visible from the road towards Yingxiu. c-d Landslide scarps at the hills surrounding the water reservoir of Zipingpu Dam

areas of steep mountain slopes have suffered many large landslides (Fig. 16). The size and number of landslides verify the extensive ground shaking experienced in the area during the main shock.

Similarly, Beichuan is surrounded by steep mountains, and the city sustained significant damage as a result of a large number of landslides and rock falls (Fig. 17). Large volumes boulders and large blocks have caused severe damage both to infrastructure (blocking roads and tearing down communication lines) and to buildings in the city. Several landslide scarps were visible in the city (Fig. 17a-c). We saw several structures in the city, which appeared to have withstood the strong ground shaking but were later destroyed by the triggered landslides. An example of this is shown in Fig. 17d, where an apartment building is completely destroyed by a landslide, while the two neighboring buildings are still standing, one of them without any apparent structural damage. Also, large blocks from the rock falls caused damage to the infrastructure blocking the roads leading in and out of the city (Fig. 17e,f).

\subsubsection{Debris flow on September 21, 2008 (Beichuan)}

On September 21, 2008, Beichuan was struck by a large debris- and mudflow which covered the SW part of the city with up to $3 \mathrm{~m}$ of debris material and mud (Fig. 18). The debris flow did not cause further structural damage to the buildings in the area (comparing Fig. 18a,b). However, the roads in the city were covered by the large amount of debris material and mud, making it difficult to get around in the city. Broken trees were brought to the city from the mountain sides, creating a natural dam (Fig. 18c,d). Houses located in the debris flow area had diagonal cracks in the walls caused by the strong ground shaking during the earthquake 

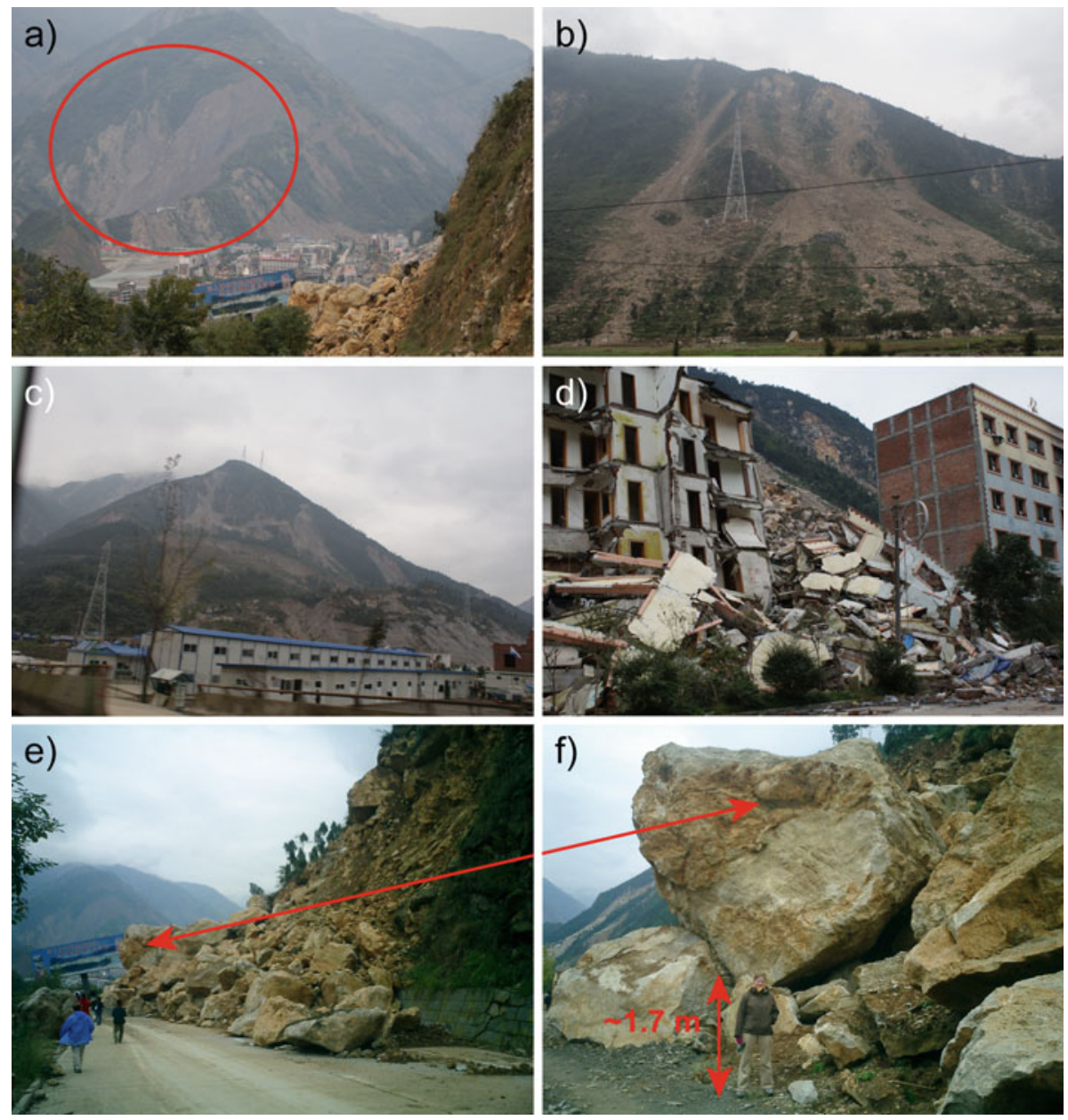

Fig. 17 Landslides and rock falls in Beichuan. a-c Landslide scarps visible on the steep mountain slopes surrounding Beichuan. Temporary shelters are visible in the foreground of (c). d Landslide in the center of Beichuan, causing an apartment block to total collapse. To the right a building with no apparent damage is visible. e-f Large rock falls and boulders blocking the road to Beichuan, notice the huge size of the boulder in $(\mathbf{f})$

(Fig. 18c). In the older part of the city, towards the river, there was a large row of damaged houses surrounded by debris material, where rubble from damaged structures has been transported to the central part of the city during the debris flow (Fig. 18d).

The strength of the debris- and mudflow was evident by the many splatter stains of mud on the in- and outside the buildings within the debris flow area. Tree trunks inside the buildings indicate that the debris flow penetrated houses (Fig. 19a,b). The structural damage to the buildings, as well as tilted or toppled houses within this area, were probably caused by the strong ground shaking during the earthquake rather than the debris flow. Due to the huge amount of debris material covering the area, the lower floors of the buildings were buried in mud (Fig. 19a,c and d). Within the debris flow area, large rock bodies, which have fallen from the mountain sides, as well as cars and other objects, were visible (Fig. 19d-f). 


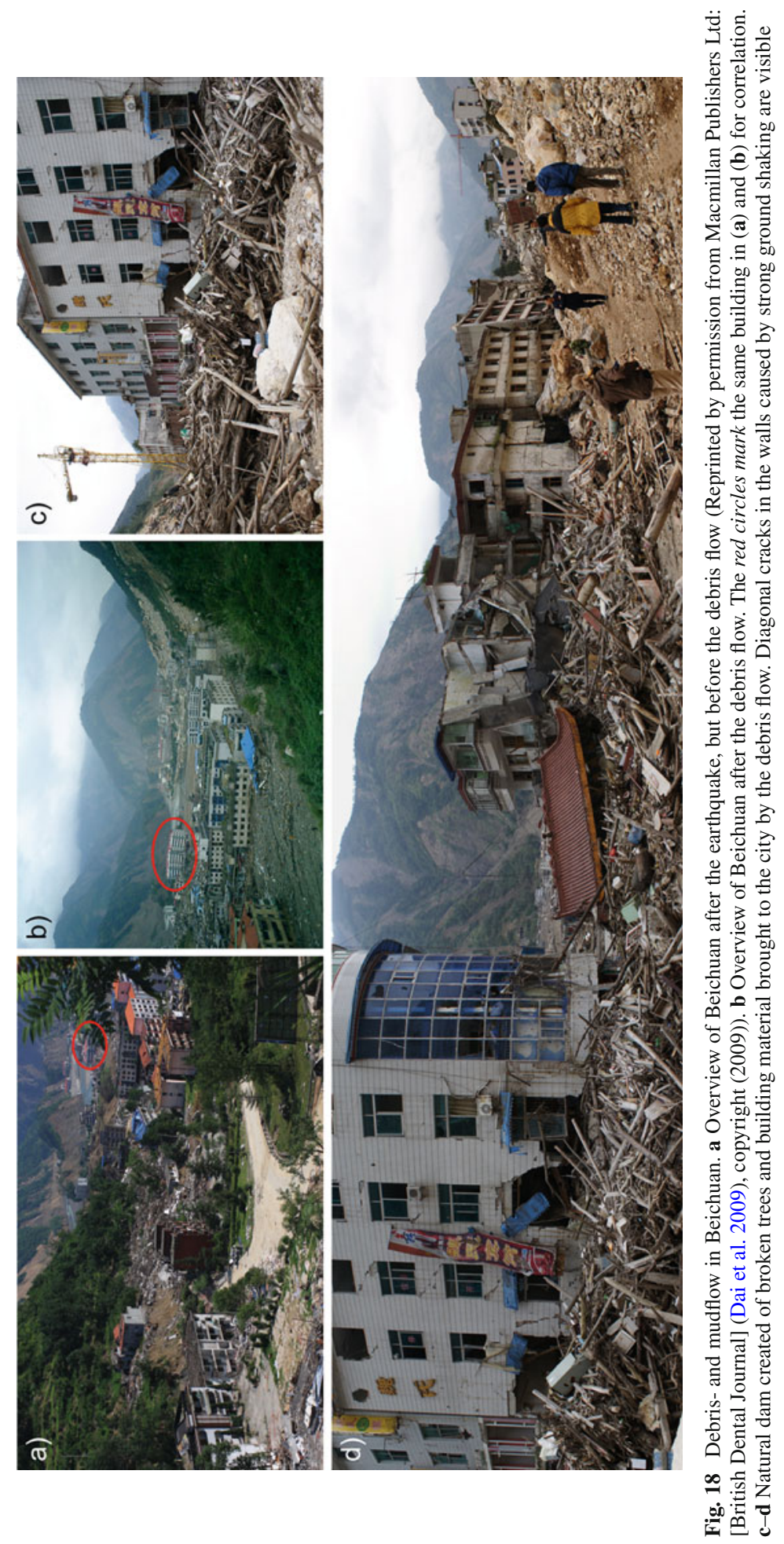



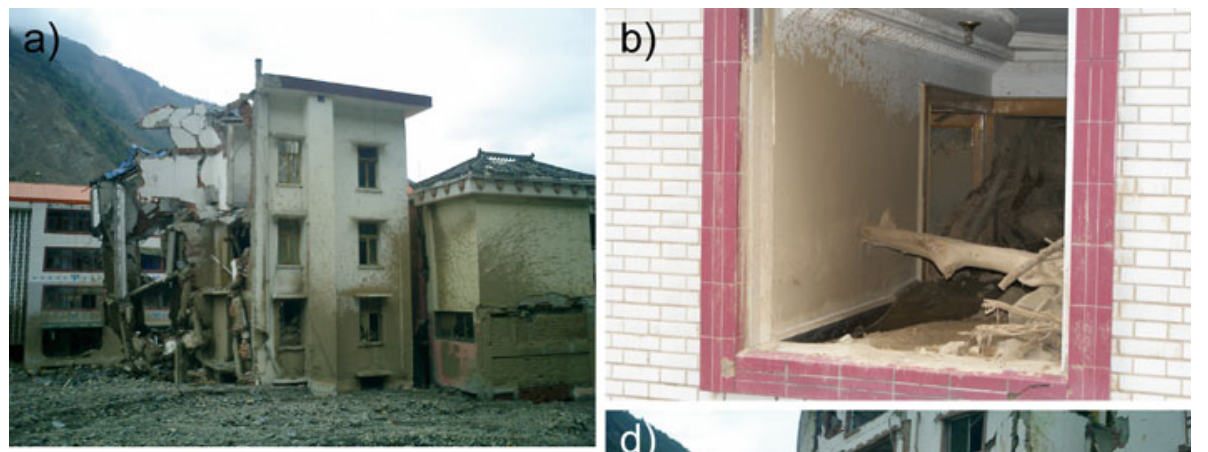

c)
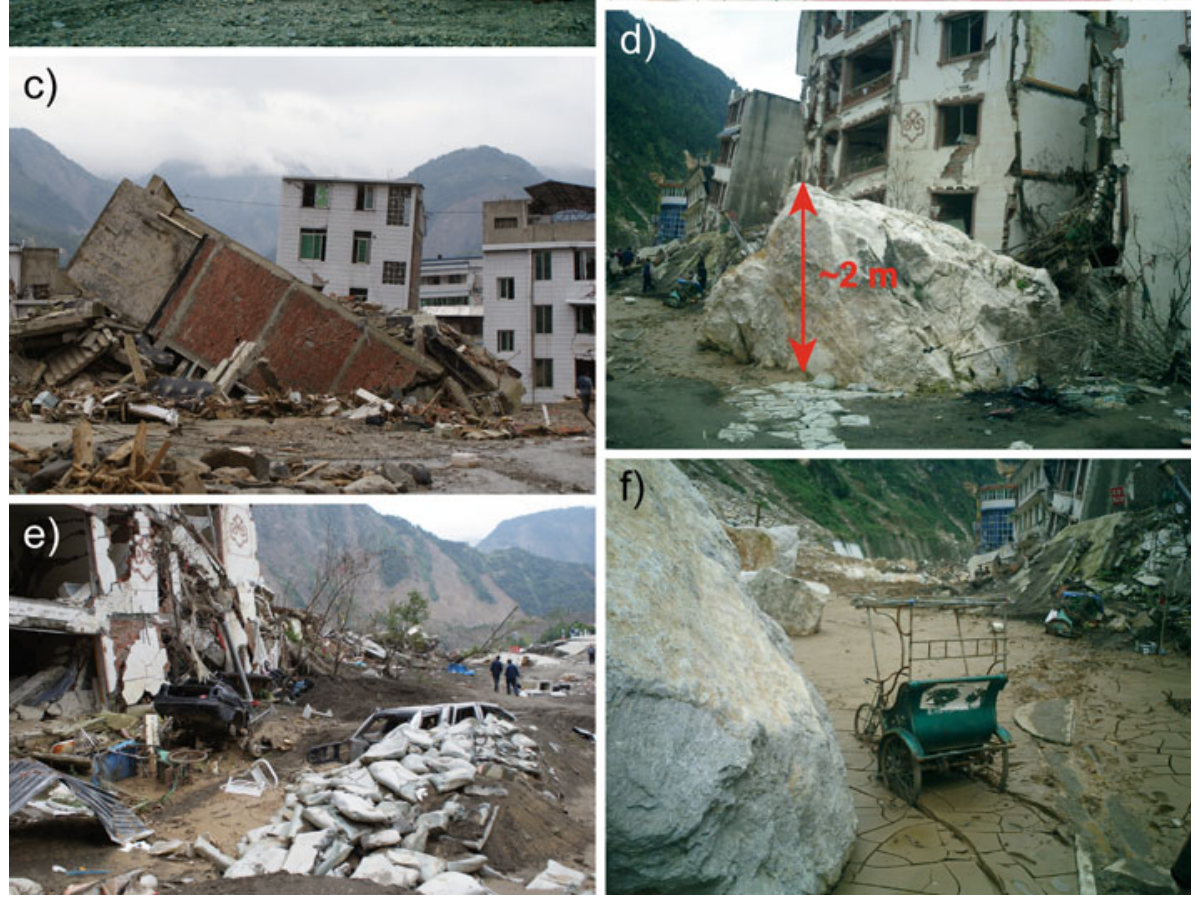

Fig. 19 Debris- and mudflow in Beichuan. a-b Splatter stains of mud on outer and inner walls of houses in the debris area verifying the strength of the event. $\mathbf{c}$ Toppled building in the old part of Beichuan due to ground failure during the ground shaking. d-f large boulders, cars and other objects stuck in the thick layer of mud and debris material. In $\mathbf{d}$ and $\mathbf{e}$ buildings with extensive damage due to strong ground shaking is visible

Several observations of liquefaction during the Wenchuan earthquake have been reported along the fault rupture (Zifa et al. 2008). During the field trip, we observed indicators of liquefaction near Beichuan (Fig. 20a). Here, a wall along the road has sunk into the liquefied sand and the concrete road was broken in a large area due to the liquefied base. The roads were in many places constructed of large concrete blocks, these were often fractured or suffered from buckling (Fig. 20b).

\subsection{Human consequences, societal response and reconstruction}

The field reconnaissance was conducted roughly 5 months after the Wenchuan earthquake, and the immediate emergency rescue had therefore already been completed. Memorial sites 

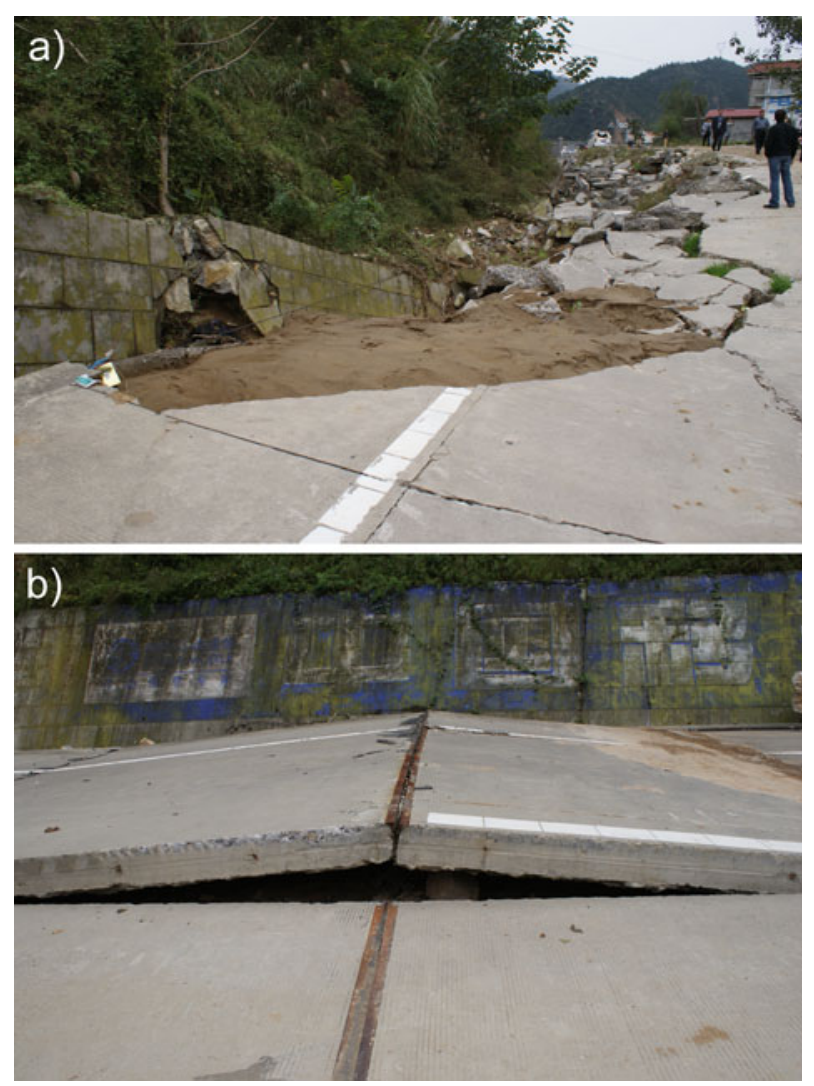

Fig. 20 a Evidence of liquefaction, where the wall and road has sunk into the sand. b Buckling of concrete road blocks

of the earthquake had been set up in every city we visited. During the months following the earthquake many large temporary shelter towns were established, serving as homes for the survivors of the earthquake. Additionally, tents and more unstable self-constructed shelters were also present throughout the area.

An enormous number of people were killed or injured in Beichuan as a result of the earthquake and the landslides that followed. A mass grave was established in the central part of the city where a new building was under construction at the time of the earthquake (Fig. 21a). During our visit in Beichuan, we observed several people entering damaged and tilted houses to collect their belongings (e.g. the building shown in Fig. 10f), and the survivors were still carrying belongings from the valley and over the mountain side to the temporary shelter towns (Fig. 21b,c).

In Yingxiu, in the epicentral area, two large temporary shelter towns had been constructed; one covering a large part of the valley south of the city (Fig. 22a-d), the other on top of a nearby hill. New schools and activities for the children were established, and large gardens were available for growing vegetables for the surviving population. The memorial site for the earthquake was located on the hill side, between the upper and lower shelter town (Fig. 22e). In addition to the large number of shelters provided by the authorities, there were several self-constructed shelters/tents of various qualities. In Yingxiu, the shelter shown in Fig. 22f, was situated only few meters from the fault scarp shown in Fig. 3a. 

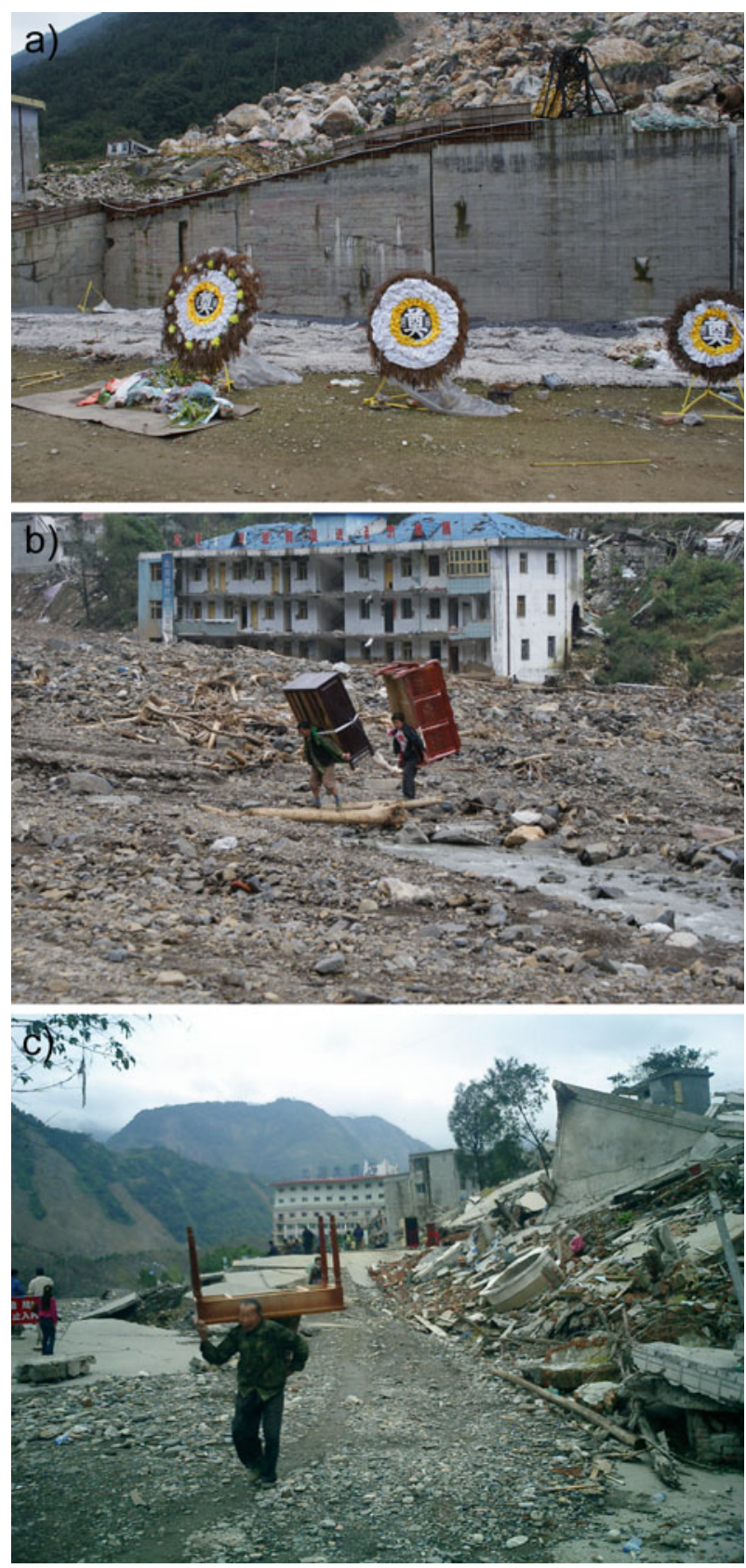

Fig. 21 a Mass grave and memorial site in the center of Beichuan. b-c Survivors gathering belongings in Beichuan and carrying them out of the city valley to the newly constructed temporary shelter town on the mountain side south of the city

The reconstruction of the earthquake affected area was still ongoing at the time of our visit. The authorities have provided building material for construction of new houses to the survivors, an example of this is given in Fig. 23a. Reconstruction was usually done by the 

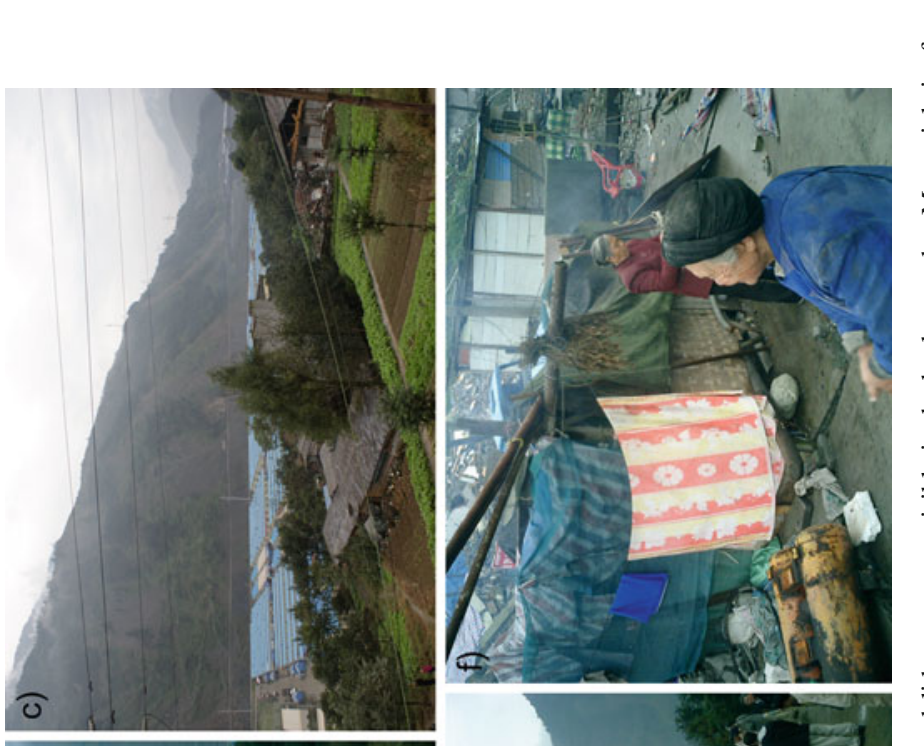

.
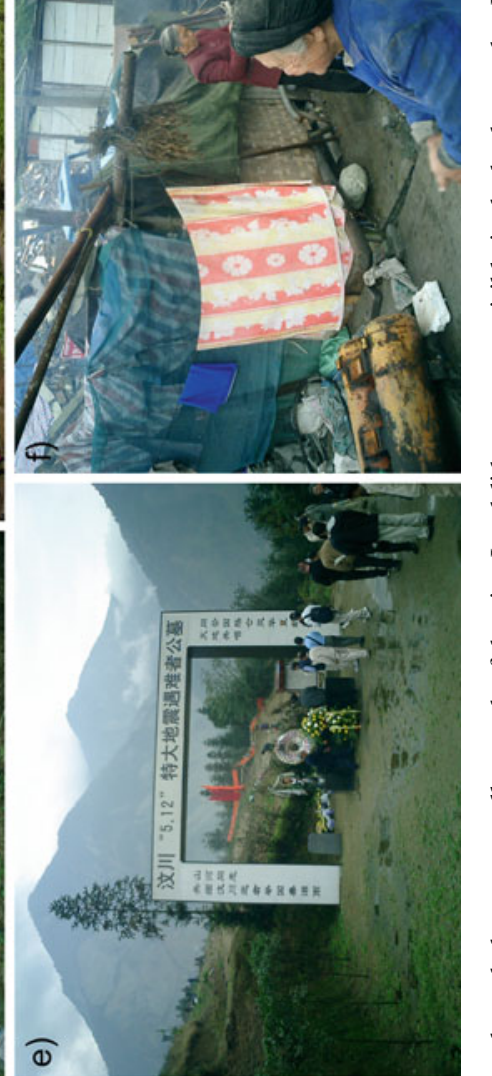

อ
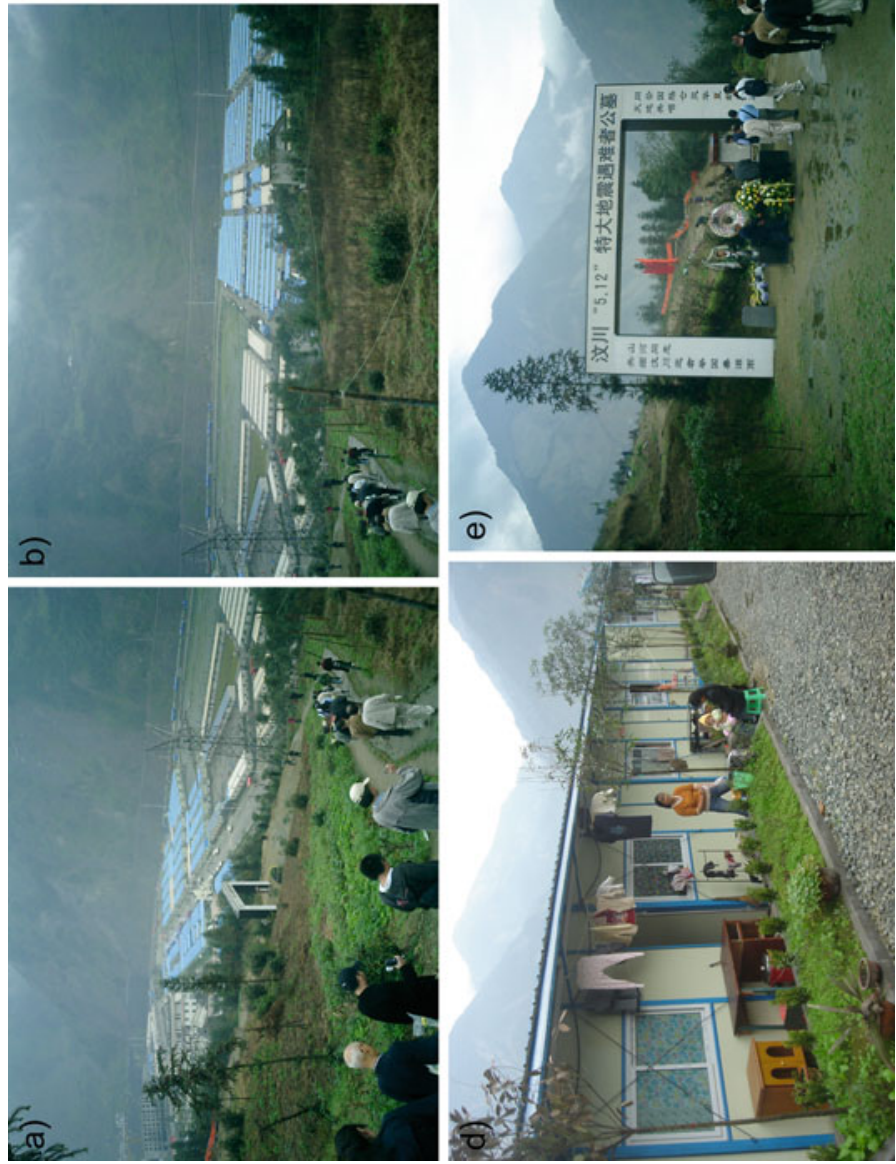

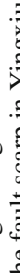

壱

․

도용

해

当吾

然

롤

范

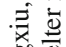

잉

$\doteq \frac{\pi}{\infty}$

$\rightarrow$ 可

苛

a

言

을

牙

要

곶

品:

을

ํㅗ

站

ส 햐

ํㅗㄷ 

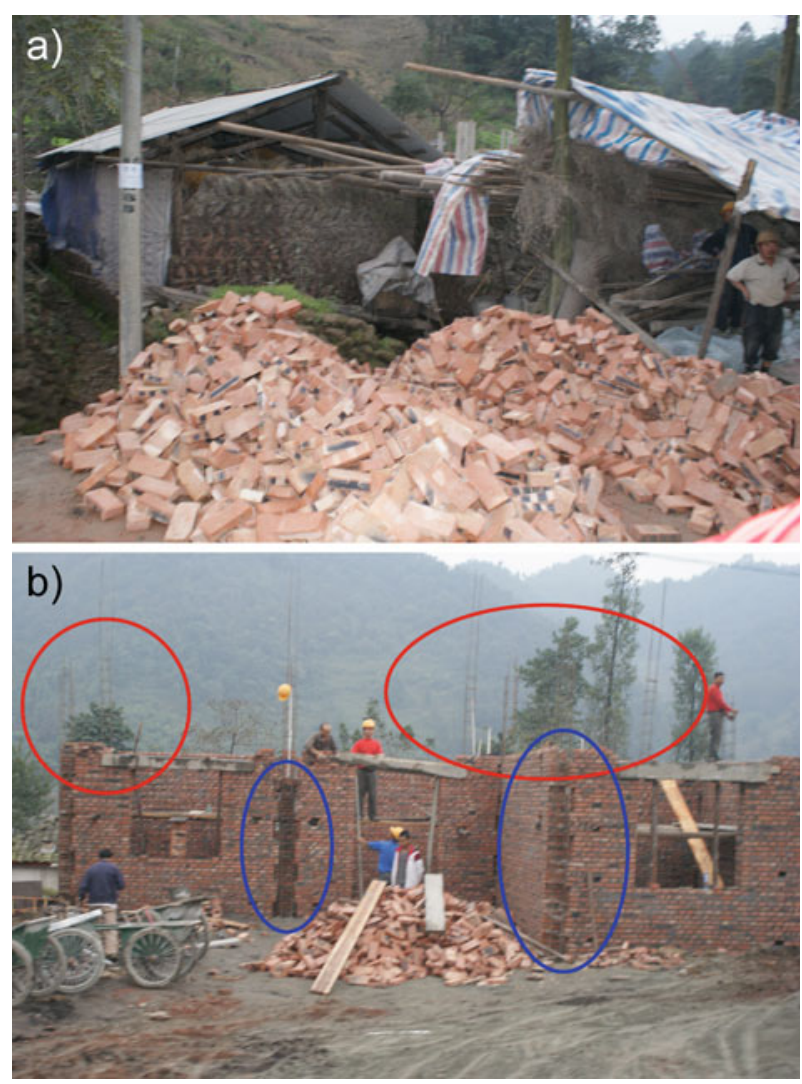

Fig. 23 Reconstruction work near Bailu. a Piles of bricks visible along the road. b Construction of simple reinforced concrete building with brick infill. Notice the concrete columns in the corners (marked with blue and red circles) are until now only visible due to the simple metal structure, while the concrete columns have not yet been made

local population as in Fig. 23b, and most of the structures were either of brick-reinforced concrete type or brick-wood type. The vulnerability of these structures in future earthquakes is expected to be high.

\section{Preliminary ground motion simulation of the Wenchuan earthquake}

During the reconnaissance trip, it became clear that the strong ground shaking was widespread and varied significantly over the affected area. In order to understand this variation, we have conducted a preliminary ground motion simulation study of the Wenchuan earthquake, applying a hybrid broadband simulation technique (Pulido and Kubo 2004).

\subsection{Ground motion simulation methodology}

We calculate the ground shaking during the Wenchuan earthquake in the frequency range $0.1-10 \mathrm{~Hz}$, following the approach by Pulido and Kubo (2004) and Pulido et al. 2004. This method has previously been validated in forensic e.g. for the 2000 Tottori (Japan) and 2004 
Sumatra (Indonesia) earthquakes (Pulido and Kubo 2004; Sørensen et al. 2007). The simulation is separated into two frequency ranges; low frequencies $(0.1-1.0 \mathrm{~Hz})$ and high frequencies $(1.0-10 \mathrm{~Hz})$. Ground motion is modeled using a finite fault model with high-slip asperities embedded in a one-dimensional velocity model. The fault plane is divided into 300 subfaults, which are assumed to be point sources. The low-frequency ground motions are obtained from the deterministic wave propagation (Bouchon 1981), whereas the highfrequency ground motions are calculated using a semi-stochastic simulation methodology that combines the empirical Green's function method of Irikura (1986) with the stochastic method of Boore (1983). The total ground motion is obtained by adding the contributions from each subfault in the time domain, assuming a constant rupture velocity within each subfault. A frequency-dependent radiation pattern is assumed to enable a smooth transition from a double couple radiation pattern at low frequencies to an isotropic radiation pattern at high frequencies (Pulido and Kubo 2004). All calculations are performed for bedrock conditions, and possible site effects and topography are therefore not considered.

\subsection{Scenario earthquake parameters}

The input source model is an earthquake scenario that is defined by the geometry and geographical location of the fault and its asperities, together with the rise time, rupture velocity, stress drop and seismic moment. The crustal structure is represented by a $1 \mathrm{D}$ velocity model together with a frequency-dependent attenuation function. In this study, we have used two velocity models to represent the crustal thickening across the studied fault, from the thinner crust underneath the Sichuan Basin in the east to the thicker crust of the Tibetan Plateau in the west. Both models are adopted from Zhao and Zhang (1987). The location and the size of the asperities within the fault plane are determined using a finite fault slip model based on waveform inversion of the teleseismic records. In this preliminary study, we have adopted the finite fault model of Ji and Hayes (2008), where a thrust mechanism along the southernmost part of the fault transforms into strike-slip motion along the northern part. To accommodate this change, we have defined two fault segments with different focal mechanisms, with a dip on the southern segment of $33^{\circ}$ and on the northern segment of $65^{\circ}$ (Koketsu et al. 2009). The rake applied on the two segments is derived from the finite fault model of Ji and Hayes (2008). In order to represent the large variation of slip across the fault plane, we define two types of asperities that correspond to regions of high $(6-9 \mathrm{~m})$ and intermediate $(2-6 \mathrm{~m})$ slip. The stress drop applied to the high-slip and intermediate-slip asperities, as well as to the background rupture, has been calculated from the fault area and the seismic moment, following Pulido et al. (2004). The individual subfaults are assigned a rise time varying randomly between $2.0 \pm 0.5 \mathrm{~s}$. The rupture velocity on each subfault is sampled from the interval $2.8 \pm 0.4 \mathrm{~km} / \mathrm{s}$, in agreement with the results of Nishimura and Yagi (2008), who reported a maximum rupture velocity of $3.2 \mathrm{~km} / \mathrm{s}$. The input parameters used in the simulation are summarized in Table 1.

\subsection{Ground motion simulation results}

We have simulated waveforms on a regular grid covering the study area $\left(101-107^{\circ} \mathrm{E}\right.$; $30-34^{\circ} \mathrm{N}$ ) and extracted the peak ground motions (PGA and PGV) at every grid point to get an insight into the distribution and extent of the strong ground shaking. The PGA and PGV distributions obtained are shown in Fig. 24. The strongest ground shaking is simulated along the rupturing fault plane with the largest ground motions associated with the southernmost segment of the fault. PGA and PGV here reach values up to $930 \mathrm{~cm} / \mathrm{s}^{2}$ and $200 \mathrm{~cm} / \mathrm{s}$, 
Table 1 Input parameters used in the preliminary ground motion simulation

\begin{tabular}{ll}
\hline$M_{\mathrm{W}}$ & 8.0 \\
Seismic moment & $1.15 \cdot 10^{21} \mathrm{Nm}$ \\
Epicenter & $103.30^{\circ} \mathrm{E} / 31.1^{\circ} \mathrm{N}$ \\
Depth & $12 \mathrm{~km}$ \\
Foc. Mech. (Strike/Dip/Rake) & \\
Southern segment & $229^{\circ} / 33^{\circ} / 115^{\circ}$ \\
Northern segment & $229^{\circ} / 65^{\circ} / 180^{\circ}$ \\
Average stress drop & $3 \mathrm{MPa}$ \\
Asperity stress drop (high slip) & $14.5 \mathrm{MPa}$ \\
Asperity stress drop (interm. slip) & $8 \mathrm{MPa}$ \\
Rise time & $2.0 \pm 0.5 \mathrm{sec}$ \\
Rupture velocity & $2.8 \pm 0.4 \mathrm{sec}$ \\
$\mathrm{f}_{\text {max }}$ & $10 \mathrm{~Hz}$ \\
High frequency attenuation, Q & $100 \mathrm{f}^{0.8}$ \\
\hline
\end{tabular}

respectively. In Fig. 24b, the maximum PGV values are shifted and extended to the northeast of the fault plane as a result of rupture directivity due to the unilateral rupture towards the northeast. The continuity of maximum ground motions along the entire fault can be associated with the fault model, which has asperities distributed throughout the central part of the fault plane (Ji and Hayes 2008).

The recent installation of the Chinese National Digital Seismic Network meant that the Wenchuan earthquake was recorded by approximately 460 stations (Li et al. 2008a) and there are many near-field recordings of this earthquake. The largest ground motions were recorded by the three near-fault stations Wolong, Qingping and Baijiao, which recorded maximum values of $957.7,824.1$ and $633.1 \mathrm{~cm} / \mathrm{s}^{2}$, respectively ( $\mathrm{Li}$ et al. 2008b), which corresponds well with the maximum modeled ground motions at these locations, which are close to $1 \mathrm{~g}$, obtained from the earthquake scenario. The recorded peak accelerations at distances up to $500 \mathrm{~km}$ from the fault have been compared to empirical attenuation relations by Li et al. (2008a). This study shows that the recorded peak accelerations are generally higher than those predicted by the empirical relations, especially at distances of $100-500 \mathrm{~km}$ from the fault. Comparing our preliminary simulation results to the same empirical attenuation relations for acceleration ground motions reveals that the simulated ground motions also predict larger ground motions than the empirical attenuation relations (Fig. 25). From the distribution of peak ground acceleration obtained in this study, it is evident that the simulation successfully reproduces the maximum ground motion values near the fault, and that the simulated peak acceleration values are comparable to those recorded during the earthquake.

For more details on ground motion simulations of the Wenchuan earthquake, the reader is referred to Bjerrum et al. (2010) and Zhang et al. (2008).

\section{Discussion}

In the following paragraphs, we discuss the faulting characteristics of the earthquake, the damage observed to the built environment, the human consequences of the Wenchuan earthquake and the ongoing planned reconstruction of the earthquake affected area. 

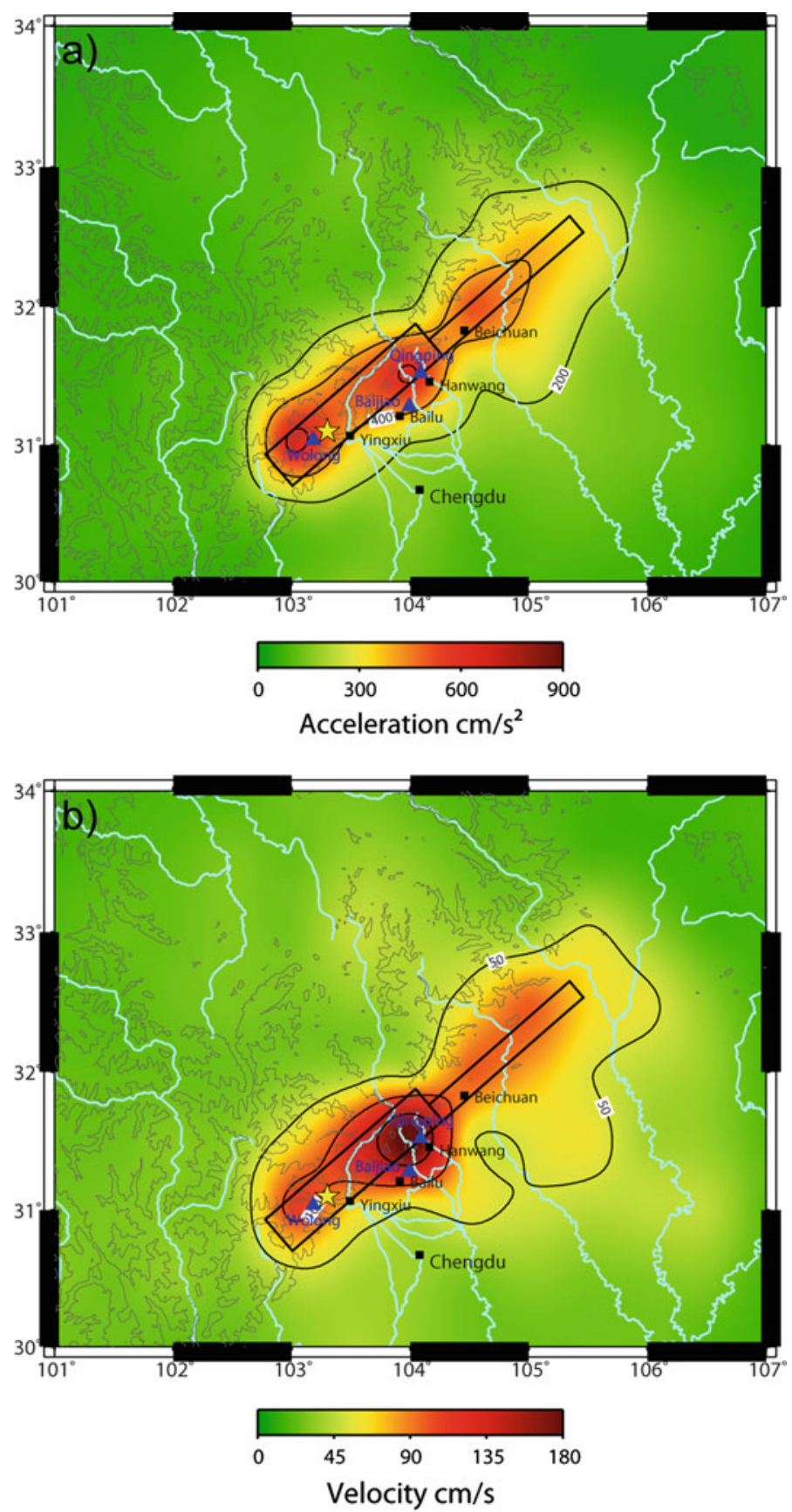

Fig. 24 Simulated a PGA and b PGV distributions in the study area. Black boxes indicate the surface projection of the fault plane. The star shows the epicenter, blue triangles indicate three seismograph stations; Wolong, Baijiao and Qingping. The black squares mark cities visited during the field trip 


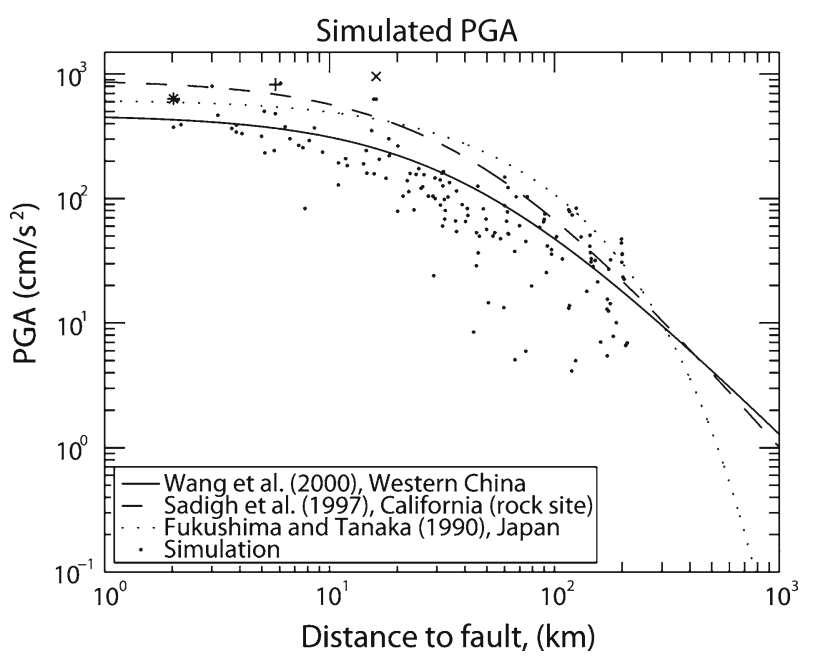

Fig. 25 Comparison of simulated PGA (black dots) to attenuation relations, of Wang et al. (2000), Sadigh et al. (1997) and Fukushima and Tanaka (1990) (see legend). The X, + and * show the recorded peak values for Wolong, Baijiao and Qingping stations, respectively

\subsection{Fault complexity}

The Wenchuan earthquake ruptured along the steep topography of the Longmenshan Mountains. Tectonically, this area is under compression due to the escape of the Tibetan Plateau towards east, overthrusting the Sichuan Basin. As a consequence, several fault strands run parallel to the mountain front (as indicated in Fig. 2), resulting in a wide area where steeply dipping thrust faults cut the surface as a part of a positive flower structure, where the parallel fault strands are connected at depth (see Hubbard and Shaw 2009, for example). Migration of such thrust faults towards the east results in the formation of several structures along the mountain range and within the Sichuan Basin that are visible in the topography. The rupture of the Wenchuan earthquake occurred along three parallel faults in the western margin of the Sichuan Basin, resulting in a complex pattern of several parallel to sub-parallel fault scarps and a large area of extensive destruction.

Waveform inversions conducted after the earthquake (e.g., Ji and Hayes 2008; Koketsu et al. 2009; Nishimura and Yagi 2008) all yield a combination of thrust and strike-slip motion during the rupture. The distribution and focal mechanisms of aftershocks $(M>5)$ reported by the ISC show the same pattern of a mixture of thrust and strike-slip mechanisms (Fig. 26). Lin et al. (2009) have conducted a field study to measure displacements along three different fault scarps following the earthquake (Yingxiu-Beichuan Fault, Guanxian-Anxian Fault and Qingchuan Fault). Their results reveal a predominant thrust movement along the Guanxian-Anxian and Qingchuan Faults, whereas large horizontal displacements were observed along the Yingxiu-Beichian Fault. This indicates a partitioning in the style of displacement to two (or more) distinct faults. Although the Wenchuan earthquake occurred within a complex tectonic setting and in an area with many sub-parallel fault strands, the ground motion simulation conducted in this study, which is based on a simple source model where average displacements of all three faults are gathered in only one plane, successfully reproduces the recorded ground shaking. 


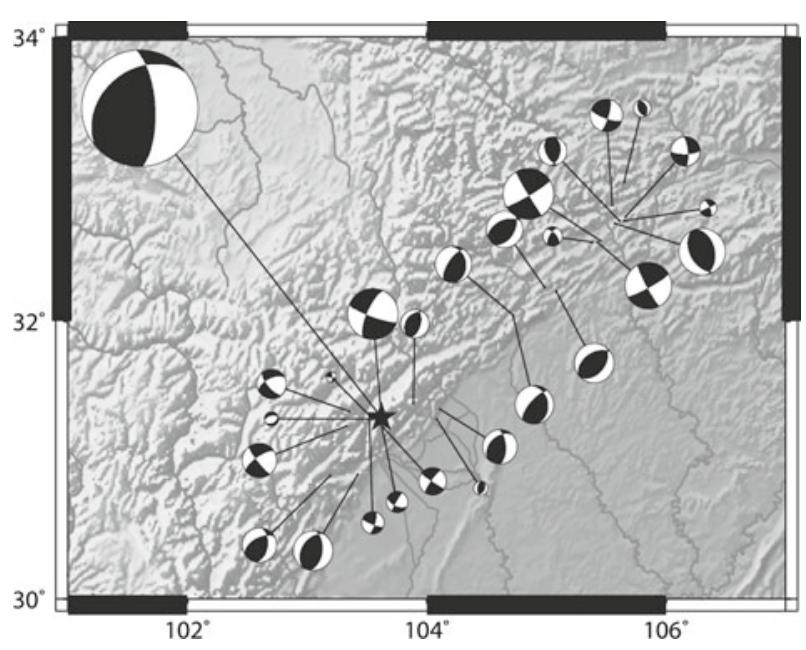

Fig. 26 Focal mechanisms of aftershocks $(M>5)$, from May 12-December 31, 2008, from ISC. The location of the main shock is shown as a star and the focal mechanism is shown in the upper left corner. Sizes of beach balls are according to magnitude

Based on the waveform inversions and the aftershock distribution, the ruptured part of the fault has been estimated to be approximately $300 \mathrm{~km}$ long. However, the estimates of the down-dip width of the fault remain uncertain. The available slip models (i.e., Ji and Hayes 2008; Koketsu et al. 2009; Nishimura and Yagi 2008) use widths varying from 40 to $80 \mathrm{~km}$. Bjerrum et al. (2010) suggest in a detailed simulation study that the fault ruptured over a fault width of approximately $40 \mathrm{~km}$. The empirical relation of Wells and Coppersmith (1994) for earthquake magnitude versus rupture area of a thrust mechanism earthquake suggests that a fault with dimensions $300 \mathrm{~km}$ along strike and $40 \mathrm{~km}$ along dip $\left(12,000 \mathrm{~km}^{2}\right)$ corresponds to an earthquake with a magnitude of $M=8.0$. If the fault width is set to $80 \mathrm{~km}$ (fault area of $24,000 \mathrm{~km}^{2}$ ), the corresponding magnitude would be $M=8.3$. Together, this supports that the $M=8.0$ Wenchuan earthquake had a fault width of approximately $40 \mathrm{~km}$.

The Longmenshan Fold and Thrust Belt in the west of the Sichuan Basin is a $400-500 \mathrm{~km}$ long fault system. The May 12, 2008 event was a unilateral rupture, which ruptured the northernmost $300 \mathrm{~km}$ of this fault system. The southernmost end of the fault system, approximately $150 \mathrm{~km}$ from the Xianshiuhe fault to Yingxiu, has not yet ruptured. Stress transfer analyses conducted following the Wenchuan earthquake have predicted a stress increase on this part of the fault system (Parsons et al. 2008; Toda et al. 2008). Using the empirical relations of Wells and Coppersmith (1994), a fault length of $150 \mathrm{~km}$ corresponds to an earthquake of $M=7.7$. Such an earthquake would have serious consequences which need to be explored in the near future.

The unilateral rupture towards northeast from Yingxiu had catastrophic consequences for the city of Beichuan. This is borne out by the high acceleration values recorded there during the event (Li et al. 2008a), which are simulated in this study. However, it is likely that because of the northeastward direction of rupture propagation, Chengdu, the state capital of Sichuan with a population of approximately 11 million, escaped without serious damage. Had the hypocenter been located in the northern part of the fault system with rupture towards southwest, it most likely would have caused much stronger ground shaking in Chengdu, leading to serious damage and human losses. 


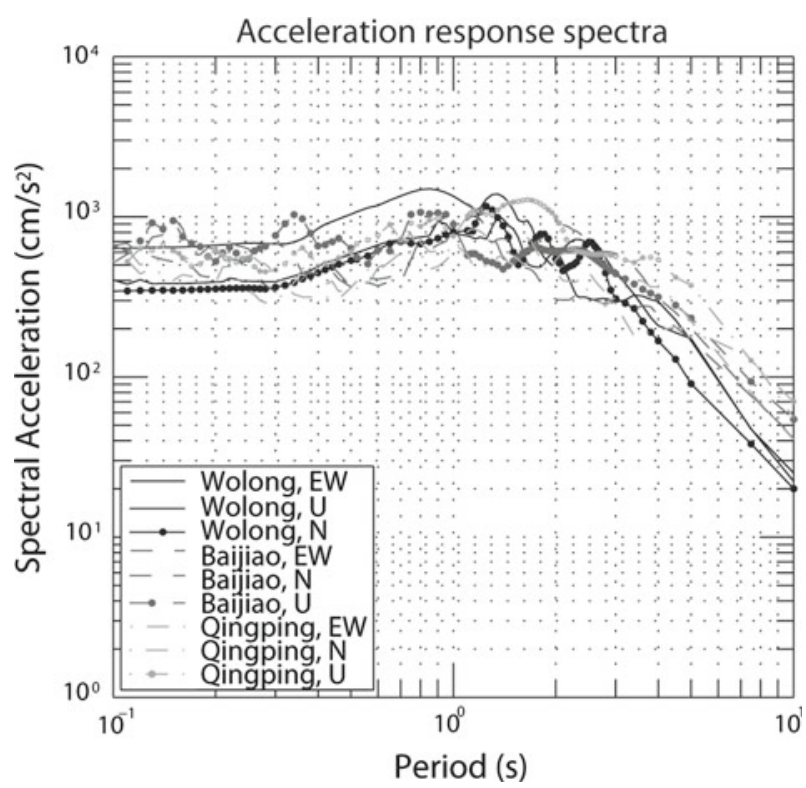

Fig. 27 Acceleration response spectra of the three stations Wolong, Baijiao and Qingping. All three components are shown (see legend for specifications). Station locations are shown in Fig. 25

\subsection{Damage to built environment}

The strong ground shaking experienced during the Wenchuan earthquake, combined with an unfavourable frequency distribution of the ground shaking, lead to the collapse of many buildings. The simulated acceleration response spectra for Wolong, Qingping and Baijiao are shown in Fig. 27. These indicate that the ground shaking had a predominant period between $0.1 \mathrm{~s}$ and $1 \mathrm{~s}$. This is in agreement with the recorded signals for which the predominant response spectral accelerations range between $0.1-0.6 \mathrm{~s}$ ( $\mathrm{Li}$ et al. 2008a).

In the area of approximately $3 \mathrm{~km}^{2}$ in the central part of Hanwang, where 90-95\% of the buildings were totally or partially collapsed (Figs. 7, 8), the typical structures were residential buildings of 4-5 stories and two-story buildings in the market area. Applying a simple empirical relation (Kramer 1996) for the typical structures in Hanwang, the predominant periods are estimated to be $0.16-0.21 \mathrm{~s}$ for two story buildings, and $0.47-0.56 \mathrm{~s}$ for five-story apartment blocks. Comparing the fundamental periods of the structures in the area to the predominant periods of the seismic signals shows a clear similarity, explaining why these buildings have not been able to withstand the ground shaking experienced in the area. On the other hand, tall structures such as the water tower (Fig. 13a), clock tower and main building of Dong Fang Steam Turbine Factory (Fig. 7a and f) with an estimated height of 15-20m, have a predominant period of $0.5-0.8 \mathrm{~s}$ and did not experience any damage. In this respect, the damage observed in the area can to a large extent be attributed to the frequency content of the ground shaking. The destruction can therefore be seen as very selective, leaving some buildings without any sign of damage, although the surrounding structures have totally collapsed. Furthermore, older buildings have suffered significant damage probably due to insufficient design codes or poor construction practices. Many of the buildings still standing in the area (for example the buildings in the background of Fig. 7d) were under construction 
at the time of the earthquake, and are assumed to be designed after the latest adequate seismic design code (Zhao et al. 2009).

In the case of Beichuan, the city suffered from an unfortunate cascade of events: strong ground shaking, landslides, rock falls and debris flow. All this, in addition to a very rough and mountainous topography, made emergency response very difficult and the city had to cope without external assistance during the first days following the earthquake. We note that the city was also unfavorably located with respect to the direction of rupture propagation. At the time of the field trip, the city was abandoned, and the surviving inhabitants had been moved from the valley to a nearby temporary shelter town. The thick cover of mud and debris material, which was transported to the area during the debris and mudflow of September 21, 2008 , poses enormous challenges in the cleaning up and reconstruction process of the city.

\subsection{Human consequences and reconstruction}

Within the earthquake affected area, large shelter towns were constructed rapidly for the survivors. Efforts of the authorities under a very efficient administration have enabled e.g. schools to be put into function soon after the earthquake, ensuring as fast as possible close-to-normal daily life. Along the roads we observed also numerous private initiatives for re-building and constructing houses. The construction practice of these structures seemed somehow questionable with respect to the basic principles of earthquake resistant design.

In order to keep the lessons learned from the Wenchuan earthquake disaster alive for the next generations, several destroyed cities in the area are planned to be kept as "Earthquake Museums" (e.g. Yingxiu, Hanwang and Beichuan), serving as memorial sites for the earthquake as well as study/field work sites for seismologists and earthquake engineers. There still exists a large task in reconstructing the damaged area and building new permanent cities for the survivors. The government has already some concrete plans for proper reconstruction of several sites following adequate seismic design codes.

\section{Conclusions}

Based on our experiences from the field trip to the selected sites in the earthquake affected area in October 2008, we can draw the following conclusions:

- Extensive damage is observed due to the shear size of the earthquake rupture and poor building construction.

- Combination of several factors such as strong ground motion, mountainous landscape, extensive landslides and rock-falls have exaggerated the human and economic consequences of this earthquake.

- Fault rupture complexity has further contributed to the intensity and distribution of damage. The rupture directivity effect had both positive and negative consequences, i.e. Chengdu has escaped significant damage, whereas Beichuan was completely devastated.

- Emergency response and rescue efforts, as well as construction of temporary sheltering for large masses of people, were successfully conducted by the Chinese authorities. However, there remain major challenges in cleaning up and permanent reconstruction of the damaged cities.

Previous seismic hazard estimates in the area have foreseen maximum macroseismic intensities of VII (Zhao et al. 2009), whereas intensities reaching IX-XI were observed during the Wenchuan earthquake. This deficiency in seismic hazard assessments for very long return 
periods points out the importance of considering also events with extremely low occurrence probabilities in seismic hazard assessment. Realistic estimates of the seismic hazard due to such events can be based on finite fault rupture scenarios. In this regard ground motions simulation methodologies, such as the one applied in this preliminary study and tested elsewhere (Bjerrum et al. 2010; Pulido and Kubo 2004; Pulido et al. 2004; Sørensen et al. 2007), can provide significant insight to the ground motion distribution and its complexity prior to such disastrous events, and can efficiently be used in earthquake preparedness programs.

Acknowledgments We would like to thank the Earthquake Administration of Sichuan Province, Sichuan Provincial Department of Construction and Sichuan Association for Science \& Technology who co-sponsored the field trip to the Wenchuan Earthquake Area for the 14th World Conference on Earthquake Engineering. We are grateful to the staff of China Earthquake Administration, Earthquake Administration of Sichuan Province, China Southwest Architectural Design and Institute Corp. Ltd., Sichuan Provincial Institute of Architectural Design, Sichuan Association for Science and Technology, Sichuan Provincial People's Hospital and the translators who made this trip possible. We would also like to thank PhD Moh Huang for locations of the stations Wolong, Baijiao and Qingping, used in the ground motion simulations. We are grateful to Nelson Pulido for comments on the engineering aspects of this study and Susanne Sargeant for proof reading and thoughtful comments. Finally, we appreciate the comments from the two anonymous reviewers.

Open Access This article is distributed under the terms of the Creative Commons Attribution Noncommercial License which permits any noncommercial use, distribution, and reproduction in any medium, provided the original author(s) and source are credited.

\section{References}

Bjerrum LW, Sørensen MB, Atakan K (2010) Strong ground motion simulation of the 12 May 2008 M 7.9 Wenchuan earthquake, using various slip models. Bull Seismol Soc Am. doi:10.1785/0120090239

Boore DM (1983) Stochastic simulation of high-frequency ground motions based on seismological models of the radiated spectra. Bull Seismol Soc Am 73:1865-1894

Bouchon M (1981) A simple method to calculate Green's functions for elastic layered media. Bull Seismol Soc Am 71:959-971

Burchfiel BC, Royden LH, vander Hilst RD, Hager BH, Chen Z, King RW, Li C, Lü J, Yao H, Kirby E (2008) A geological and geophysical context for the Wenchuan earthquake of 12 May 2008, Sichuan, People's Republic of China, GSA Today 18, 4-11

China.org.cn (2010) Casualities in SW China's worst earthquake. http://www.china.org.cn/wenchuan_ earthquake/2008-05/14/content_15220061.htm, April 2010

Dai J, Zhao Y, Li G (2009) Wenchuan earthquake: response of Chinese dental professionals. Br Dent J 206:273-276

Earthquake Administration of Sichuan Province, China (ed) (2008) Guide to the Trip to the 5.12 Sichuan Earthquake Area for the 14th World Conference on Earthquake Engineering, 18-19 October 2008

Fukushima Y, Tanaka T (1990) A new attenuation relation for peak horizontal acceleration of strong earthquake ground motion in Japan. Bull Seismol Soc Am 80:757-783

Hubbard J, Shaw JH (2009) Uplift of the Longmen Shan and Tibetan plateau, and the 2008 Wenchuan $(M=$ 7.9) earthquake. Nature 458:194-197

Irikura K (1986) Prediction of strong acceleration motion using empirical Green's functions. Paper presented at the 7 th Japan Earthquake Symposium, Japan

Ji C, Hayes G (2008) Source model of the May 12th 2008 Wenchuan earthquake. http://earthquake.usgs.gov/ eqcenter/eqarchives/poster/2008/20080512.php, July 2008

Kerr RA, Stone R (2009) A human trigger for the great quake of sichuan. Science 323:322

Koketsu K, Yokota Y, Ghasemi H, Hikima K, Miyake H, Wang Z (2009) Source process and ground motions of the 2008 wenchuan earthquake. Investigation report of the 2008 Wenchuan Earthquake, China, Grantin-Aid for Special Purposes of 2008, MEXT. http://shake.iis.u-tokyo.ac.jp/wenchuan/, June 2009

Kramer SL (1996) Geotechnical earthquake engineering. Prentice Hall Inc, New Jersey

Lei X, Kuwahara Y (2008) Seismological aspects of the Wenchuan earthquake, China. Grant-in-Aid for Special Purposes of 2008, MEXT. http://shake.iis.u-tokyo.ac.jp/wenchuan/, June 2009 
Li X, Zhou Z, Huang M, Wen R, Yu H, Lu D, Zhou Y, Cui J (2008) Preliminary analysis of strong-motion recordings from the magnitude 8.0 Wenchuan, China, Earthquake of 12 May 2008. Seismol Res Lett 79:844-854

Li X, Zhou Z, Yu H, Wen R, Lu D, Huang M, Zhou Y, Cu J (2008) Strong motion observations and recordings from the great Wenchuan Earthquake. Earthq Eng Eng Vib 7:235-246

Lin A, Ren Z, Jia D, Wu X (2009) Co-seismic thrusting rupture and slip distribution produced by the 2008 Mw 7-9 Wenchuan earthquake, China. Tectonophysics 471:203-215

Nishimura N, Yagi Y (2008) Rupture process for May 12, 2008 Sichuan earthquake (Ver. 2). Japan University of Tsukuba, http://www.geol.tsukuba.ac.jp/ nisimura/20080512/, June 2008.

Parsons T, Chen J, Kirby E (2008) Stress changes from the 2008 Wenchuan earthquake and increased hazard in the Sichuan basin. Nature 454:509-510

Pulido N, Kubo T (2004) Near-fault strong motion complexity of the 2000 Tottori earthquake (Japan) from a broadband source asperity model. Tectonophysics 390:177-192

Pulido N, Ojeda A, Atakan K, Kubo T (2004) Strong ground motion estimation in the Sea of Marmara region (Turkey) based on a scenario earthquake. Tectonophysics 391:357-374

Sadigh K, Chang C Y, Egan JA, Makdisi F, Young RR (1997) Attenuation relationships for shallow crustal earthquakes based on California strong motion data. Seism Res Lett 68:180-189

Sørensen MB, Atakan K, Pulido N (2007) Simulated Strong Ground Motions for the Great M 9.3 SumatraAndaman Earthquake of 26 December 2004. Bull Seismol Soc Am 97:S139-151

Toda S, Lin J, MeghraouiM Stein RS (2008) 12 May $2008 M=7.9$ Wenchuan, China earthquake calculated to increase failure stress and seismicity rate on three major fault systems. Geophys Res Lett 35:L17305. doi:10.1029/2008GL034903

USGS (2009) Magnitude 7.9 - Eastern Sichuan, Chian. http://earthquake.usgs.gov/eqcenter/eqinthenews/ 2008/us2008ryan/\#summary, June 2009

USGS Landslide Hazard Program (2009) Landslides From the Sichuan (Wenchuan) Earthquake, China, May 2008. http://landslides.usgs.gov/learning/photos/international/landslides_from_the_sichuan_ wenchuan_earthquake_china_may_2008, September 2009

Wang SY, Yu YX, Gao AJ, Yan XJ (2000) Development of attenuation relations for ground motion in China. Earthquake Research in China 16:99-106; (in Chinese)

Wells DL, Coppersmith KJ (1994) New empirical relationships among magnitude, rupture length, rupture width, rupture area, and surface displacement. Bull Seismol Soc Am 84:974-1002

Yin Y, Wang F, Sun P (2009) Landslide hazards triggered by the 2008 Wenchuan earthquake, Sichuan, China. Landslides 6:139-152

Zhang P, Yang ZX, Gupta HK, Bhatia SC, Shedlock KM (1999) Global seismic hazard assemssment program (GSHAP) in continental Asia. http://www.seismo.ethz.ch/GSHAP/eastasia, April 2010

Zhang W, Shen Y, Chen X (2008) Numerical simulation of strong ground motions for the Ms 8.0 Wenchuan earthquake of 12 May 2008. Sci China Ser D Earth Sci 51:1673-1682

Zhang Z, Cheng W, Ruan X, Wu P (2009) The seismicity and tectonic stress field characteristics of the Longmenshan fault zone before the Wenchuan Ms8.0 earthquake. Earthq Sci 22:119-128

Zhao B, Taucer F, Rossetto T (2009) Field investigation on the performance of building structures during the 12 May 2008 Wenchuan earthquake in China. Eng Struct 31:1707-1723

Zhao CP, Chen ZL, Zhou LG, Li ZX, Kang Y (2010) Rupture process of the Wenchuan M8.0 earthquake of Sichuan China: the segmentation feature. Chinese Sci Bull 55:284-292

Zhao Z, Zhang R (1987) Preliminary study of crustal and upper mantle velocity structure of Sichuan Province. ACTA Seismologica Sinica 9:99-106; (in Chinese)

Zifa W (2008) A preliminary report on the Great Wenchuan Earthquake. Earthq Eng Eng Vib 7:225-234

Zifa W, Chunfeng H, Baitao S, Xiaojun L, Yifan Y, Minzheng Z, Shanyou L, Xiaoxin W, Yong LS, Jianguo X, Mingyu Z, Lili X, Zhenpeng L (2008) General introduction to engineering damage during Wenchuan earthquake. In: Lili X (ed) Supplement to Earthquake Eng. Eng. Vib. Science Press, Beijing p 114 